\title{
Post-mortem analysis of tungsten plasma facing components in tokamaks: Raman microscopy measurements on compact, porous oxide and nitride films and nanoparticles.
}

\author{
C. Pardanaud ${ }^{a}$, D. Dellasega ${ }^{b, c}$, M. Passoni ${ }^{\text {b,c }}$, C. Martin ${ }^{a}$, P. Roubin ${ }^{a}$, Y. Addab ${ }^{a}$, C. Arnas ${ }^{a}$, L.
}

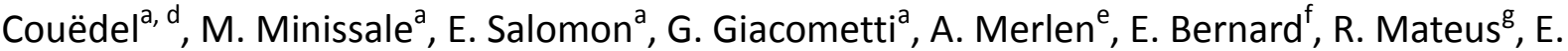
Alves $^{g}$, Z. Siketic ${ }^{h}$, I. Bogdanovic Radovic ${ }^{h}$, A. Hakola', and EUROfusion WP PFC contributors ${ }^{j}$

\author{
${ }^{a}$ Aix Marseille Univ, CNRS, PIIM, Marseille, France \\ ${ }^{b}$ Dipartimento di Energia, Politecnico di Milano, Milano, Italy \\ "Istituto di Fisica del Plasma "P.Caldirola", Consiglio Nazionale delle Ricerche, Milano, Italy \\ ${ }^{d}$ Phys. and Eng. Phys. department, University of Saskatchewan, Saskatoon SK S7N 5E2, Canada \\ ${ }^{e}$ Aix Marseille Univ, Université de Toulon, CNRS, IM2NP, Marseille, France \\ ${ }^{f}$ CEA, IRFM, F-13108 Saint Paul lez Durance, France \\ ${ }^{g}$ Instituto Superior Técnico, Universidade de Lisboa, Bobadela, Portugal \\ ${ }^{h}$ Rudjer Boskovic Institute, P. O. Box 180, 10002 Zagreb, Croatia \\ 'VTT, P. O. Box 1000, 02044 VTT, Finland \\ 'See the author list in "S. Brezinsek et al 2017 Nucl. Fusion 57 116041"
}

\section{Abstract}

Raman microscopy is one of the methods that could be used for future post-mortem analyses of samples extracted from ITER plasma facing. This study shows that this technique is useful for studying tungsten-based materials containing impurities including oxides and nitrides. Here, we apply pulsed laser deposition and DC argon glow discharges to produce tungsten-containing synthetic films (compact, porous) and nanoparticles and investigate the influence of their morphology on the measured Raman spectra. The amounts of oxygen and/or nitrogen in the films are also investigated. Comparative data are obtained by X-ray Photoelectrons Spectroscopy, Atomic Force Microscopy, Electron Microscopies (Scanning and Transmission), Energy Dispersive X-ray spectroscopy, Time-of-Flight Elastic Recoil Detection Analysis. The power density of the laser beam used to perform Raman microscopy is varied by up to 4 orders of magnitude $\left(0.01-20 \mathrm{~mW} / \mu \mathrm{m}^{2}\right)$ to investigate thermal stability of films and nanoparticles. As a first result, we give evidence that Raman microscopy is sensitive enough to detect surface native oxides. Secondly, more tungsten oxides are detected in porous materials and nanoparticles than in compact films, and the intensities of the Raman band correlate to their oxygen content. Thirdly, thermal stability of these films (i.e. structural and chemical modification under laser heating) is poor when compact films contain a sufficiently large amount of nitrogen. This finding suggests that nitrogen can be substituted by oxygen during Raman laser induced heating occurring in ambient air. Finally, our methodology can be used to rapidly characterize morphology and chemistry of the samples analyzed, and also to create oxides at the micrometer scale.

keywords: PLD, Raman spectroscopy, tungsten oxide, tungsten nitride, plasma wall interaction, laser heating, post-mortem analysis 


\section{Introduction}

Tungsten is one of the elements that will be used in the fabrication of plasma facing components (PFC) for the ITER tokamak. It has been chosen due to its good thermomechanical properties and low affinity with hydrogen isotopes in order to face the high heat due to nuclear fusion reactions between hydrogen isotope nuclei $[1,2]$. Heat fluxes, in the range 10 to $20 \mathrm{MW} / \mathrm{m}^{2}$ in steady state operations and even higher (in the $\mathrm{GW} / \mathrm{m}^{2}$ ) for edge localized modes or other transients will have to be radiated off $[3,4]$, mainly on the divertor [5]. However, due to plasma wall interactions [6], PFC characteristics will be modified during the lifetime of the machine [7] due to the many simultaneous processes (erosion, morphological changes, melting, defect formation...), involving high heat fluxes, impinging ions and neutrals [8] formed by hydrogen isotopes (fuel of the reaction), helium (ashes of the reaction), neutron bombardment... and will modify the PFCs. The presence of impurities such as oxygen or nitrogen, and eroded species that can migrate or redeposit $[9,10]$ should also be taken into account. As a result, PFCs will react chemically (for example forming oxide layers in specific conditions [11, 12], with seeding gas [13, 14]), melting being a possibility that can enhance those chemical effects. As a consequence, the safety conditions of ITER may be compromised, mainly due to the formation of dusts [15-17] and retention of radioactive tritium used to fuel the plasma [18-20]. The prediction of how these modifications will alter long term operations is thus a keystone in the field. To this end, two complementary strategies are generally used. The first one involves testing scenarios in existing tokamaks, e.g., in the JET tokamak with ITER like wall (ILW) configuration [21] or in the WEST tokamak [22, 23], and then using scaling laws to predict what could happen under ITER conditions. The second one involves testing for PFC and/or laboratory materials for one specific or several synergetic effects together, in facilities [24, 25] allowing controlled parameters (surface temperature, morphology, composition, ion flux and energy...) [26-29]. In this article, synthetized materials are produced to mimic deposits or modified surfaces [6].

Post-mortem analyses are then used for all the samples to obtain a before/after comparison. Traditionally used techniques include ion beam analyses [30] and thermal desorption spectroscopy that give the concentrations and depth distributions of various elements, electron microscopy, that gives information on the morphology/porosity and Xray diffraction (XRD) that reveals the structure of and nature of traps in the material [31, 32]. 
In addition, we use Raman microscopy. This technique is based on an inelastic light scattering process and is highly sensitive to chemical composition, structure and morphology. Depending on the optical constants of the probed material, Raman microscopy can be sensitive to the near surface (few tens of nanometers in the case of metals) with a micrometer lateral resolution, that allows monitoring spatial inhomogeneities [11, 12$]$. Raman microscopy method gives information about atomic vibrations, and is thus able to distinguish chemical bonds in the solids and to reveal how hydrogen isotopes and impurities are bonded, either to metal atoms or to each other's $[33,34]$. It is particularly sensitive to detect tungsten oxides and the modifications of their characteristic structure and composition after $\mathrm{He}$ or $\mathrm{D}$ implantation [35-37], as well as to detect the presence of $\mathrm{H}$ in oxides [38]. It is also sensitive to the crystalline structure and the presence of defects [39].

In this work, we focus on both the detection of impurities in tungsten by means of Raman microscopy and the influence of material surface roughness on the measured spectra. We use a large variety of laboratory samples: pulsed laser deposition (PLD) grown W films with different morphologies (porous or compact) and different chemical compositions (with different $\mathrm{O}$ and $\mathrm{N}$ contents), $\mathrm{W}$ nanoparticles and a $\mathrm{W}$ bulk ITER-grade sample and thick $\mathrm{WO}_{3}$ layers. This work is a continuation of our previous work [40] demonstrating that Raman microscopy gives a reliable detection of oxides for Be based samples $[11,12]$ and for W based samples. It is therefore a well-suited technique for post-mortem analyses of ILW PFCs. In addition, in this study, by varying the power of the incident laser by up to 4 orders of magnitude, we can study the fingerprint of laser irradiation on the Raman spectra. It allows us quickly retrieve information about the morphologies of $\mathrm{O}$ and $\mathrm{N}$ containing $\mathrm{W}$ films. This is due to structural changes that laser heating induces when thermal dissipation is not efficient, which is the case of porous samples.

\section{Methods}

\subsection{Sample preparation}

For this study, we synthetized and analyzed $11 \mathrm{~W}$ based samples, containing various amounts of $\mathrm{O}$ and $\mathrm{N}$. We compared them to a polycrystalline tungsten sample provided by A.L.M.T. Corp (Japan) with a mirror-like polishing and a set of $\mathrm{WO}_{3}$ tungsten oxide layers obtained by thermal oxidation of $\mathrm{W}$ under $\mathrm{O}_{2}$ pressure (see [35] for details) with thicknesses 
varying from 20 to $200 \mathrm{~nm}$. From the batch of 11 samples, 1 was composed of agglomerated nanoparticles, deposited by magnetron DC sputtering (see [41] for details), while the 10 others were produced by Pulsed Laser Deposition (PLD). Varying the experimental conditions allowed changing their chemical composition (amount of $O$ in the bulk varied from 0 to 60 atomic \% and/or the amount of $\mathrm{N}$ from 0 to 20 atomic \%), and their morphology (compact or porous with a cauliflower like structure). The PLD samples were produced as thin films on metallic substrates (stainless steel or Mo) using a $532 \mathrm{~nm}$ laser in the nanosecond regime (5$7 \mathrm{~nm}, 10 \mathrm{~Hz}$, pulse energy $700 \mathrm{~mJ}$ ), focused on a $\mathrm{W}$ target (purity 99.99\%) with an energy density of $15 \mathrm{~J} / \mathrm{cm}^{2}$. The species ablated from the target expanded in the vacuum chamber (base pressure of $10^{-3} \mathrm{~Pa}$ ) and ended up on the substrate, located $60 \mathrm{~mm}$ away from the target. All the films were deposited at room temperature. The depositions were performed in different background atmospheres and pressures ( $\mathrm{Ar}, \mathrm{He}$ and $\mathrm{N}_{2}$ and with pressure in the range 2.5-70 $\mathrm{Pa}$ ). The use of different process gas results in different film morphologies: compact amorphous (c-) or porous (p-) and compositions. Further details are reported in [42, 43]. Thickness of these samples was $\approx 1 \mu \mathrm{m}$. The synthesis conditions and bulk compositions are reported for the samples studied in table 1.

\subsection{Sample characterization}

The morphology of the 10 PLD samples has been assessed by a ZEISS Supra 40 scanning electron microscope (SEM) using an accelerating voltage of 5- $7 \mathrm{kV}$, as will be presented in more details in section 3. Nanoparticles have been studied using transmission electron microscopy (TEM). A CS corrected FEI 80-300 device is used to acquire high resolution electron micrographs (HR TEM) [41]. Bulk elemental composition of the 10 PLD films has been obtained by Time-of-Flight Elastic Recoil Detection Analysis (TOF ERDA) and/or Energy Dispersive X-ray spectroscopy (EDX). The EDX system used is an Oxford Instruments $\mathrm{Si}(\mathrm{Li})$ detector in combination with the SEM microscope. The TOF-ERDA measurements were performed using a $6 \mathrm{MV}$ Tandem Van de Graaff accelerator located at the Ruđer Bošković Institute, Zagreb. For the analysis $20 \mathrm{MeV}^{127} \mathrm{I}^{6+}$ ions at a $20^{\circ}$ incidence angle toward the sample surface were used, allowing to measure down to $300 \mathrm{~nm}$ in the bulk. The TOF-ERDA spectrometer was positioned at an angle of $37.5^{\circ}$ toward the beam direction. More details about the experimental setup can be found in $([44,45])$. Note that the samples $c$ WO $(25,2)$ and $p \mathrm{WO}(60,2.5)$ were previously analyzed in [46]. Atomic force microscopy (AFM) was used 
to study the roughness of the samples. Here, the tapping mode of an NTMDT solver was used, the tip radius was $\approx 10 \mathrm{~nm}$, and the vertical and horizontal resolutions were $\approx 1$ and $\approx$ $10 \mathrm{~nm}$, respectively. X-ray Photoelectrons Spectroscopy (XPS) analyses were performed at the PIIM laboratory. The experimental setup is composed of a high-intensity twin (Mg/Al) anode X-ray Source (provided by PREVAC) emitting at 1253.6 and $1486.6 \mathrm{eV}$ respectively. The analyzed samples were placed in a movable sample holder inside a mu-metal ultra-high vacuum chamber (base pressure $1 \times 10^{-10} \mathrm{mbar}$ ). Photoelectrons were detected via a highresolution electron energy analyzer (Scienta Omicron R3000) composed of a high transmission electron lens with an acceptance angle of 30 degrees and a $40 \mathrm{~mm} \mathrm{MCP}$ detector monitored by a FireWire CCD-Camera. The resolution of the XPS spectrometer, determined from the full-width at half maximum of the $\mathrm{Ag} 3 \mathrm{~d}$ core levels of a clean $\mathrm{Ag}$ single crystal, was $0.9 \mathrm{eV}$.

Raman spectra were recorded in the back-scattering geometry using a Horiba-Jobin-Yvon HR LabRAM HR800 Raman microspectrometer, using one laser wavelength $\lambda_{L}=514.5 \mathrm{~nm}$. The used objectives had a $\times 100$ magnification, with a numerical aperture (N.A.) of 0.9 and $\times 50$ magnification with a numerical aperture of 0.5 . The radius of the laser spot with N.A. $=0.9$ is $R \approx 0.6 \times \lambda_{\mathrm{L}} / \mathrm{N} . \mathrm{A} \approx 0.34 \mu \mathrm{m}$. To study possible heating effect, the laser power

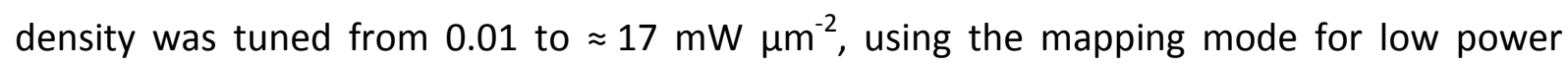
density in order to avoid any oxidation due to the probe beam as measurements were performed in air. The used grating (600 lines $/ \mathrm{mm})$ gave a spectral resolution of $\approx 1 \mathrm{~cm}^{-1}$.

\subsection{Sensitivity and capability of Raman spectroscopy for studying oxides and nitrides}

As there are only acoustic phonon branches in tungsten, and due to the spectroscopic configuration used in this study, no Raman bands are supposed to be detected, meaning this spectroscopic technique is not adequate to probe pure W. However, oxides, even if not wanted, will be present in tokamaks $[12,47]$. Then, Raman spectroscopy signal is expected to be very rich for oxides and bronzes (i.e. hydrogen in oxides) as the numerous structures listed in the literature lead to optical phonon branches. In figure 1, some typical oxide spectra are shown as well as the phonon density of states (PDOS) of pure W, which can be seen due to relaxing quantum selection rules when defects are introduced [48]. Whatever the O/W stoichiometry, the spectra are mainly composed of bands related to bending and stretching modes of W-O-W bonds, in addition to a band related to the vicinity of the surface 
[49-51]. To better understand the spectra, we need to go deeper into the details of the tungsten oxide structure. The building blocks of tungsten oxide are $\mathrm{WO}_{6}$ octahedra: $1 \mathrm{~W}$ and 4 surrounding $\mathrm{O}$ form a basal plane, and 2 out of plane $\mathrm{O}$, above and below that plane, form the octahedra. This local arrangement governs the main trends observed in the Raman spectra, especially the bands lying at 270,714 and $805 \mathrm{~cm}^{-1}$. However, these octahedra are corner- or edge-sharing to form the numerous tungsten oxide polymorphs observed in the nature and this can affect the Raman spectra as symmetry, stoichiometry and interatomic distances change. Depending on the tilting angle and rotation direction of the octahedra relative to the others [52], several $\mathrm{WO}_{3}$ phases can exist. For example, for bulk $\mathrm{WO}_{3}$, triclinic $\delta-\mathrm{WO}_{3}$ is the existing phase at low temperatures. From $17^{\circ} \mathrm{C}$ up to $330^{\circ} \mathrm{C}$, the monoclinic phase $\gamma-\mathrm{WO}_{3}$ dominates, then the orthorhombic $\beta-\mathrm{WO}_{3}$ phase up to $740^{\circ} \mathrm{C}$ where the tetragonal $\alpha-\mathrm{WO}_{3}$ starts to form. The transition temperatures can decrease when nanostructures appear $[39,49]$ and/or when the stoichiometry changes slightly from that of a trioxide [53]. Magneli phases with stoichiometries close to trioxide, from 2.625 to 2.92, have been reported earlier [54]. The aim of figure 1 is thus to give a brief overview of the main spectroscopic features and differences that characterize tungsten oxides. The vertical dashed lines give the band positions $\left(270,714\right.$ and $\left.805 \mathrm{~cm}^{-1}\right)$ of the three main Raman active modes of bulk monoclinic $\mathrm{WO}_{3}$. Subtle changes in the spectra (band position mainly) can occur depending on the $\mathrm{WO}_{3}$ phase but they are considered negligible at this step, compared to the differences that other kinds of oxides introduce in the spectra, as can be seen with a quick view in this figure. Introducing defects that diminish the crystallite size at which the octahedral periodic pattern is perfectly repeated results in broadening the peaks and increasing the intensity levels of the low frequency bands centered at $270 \mathrm{~cm}^{-1}$. This is what can be seen on the spectrum labeled $d-W_{3}, d$ standing for defective. Details of this sample synthesis can be found in [55]. For nano trioxide (labelled $\mathrm{n}-\mathrm{WO}_{3}$, with a crystallite size of 4 $\mathrm{nm}$ only, [39]), broadening further increases, resulting in the merging of the 714 and $805 \mathrm{~cm}^{-}$ ${ }^{1}$ bands, and the intensity of the low wavenumber bands diminishes. For samples labelled $\mathrm{WO}_{\mathrm{x}}[56]$, where oxygen content is low compared to that of a trioxide, the stretching mode bands are distinguishable but are overlapping and shifted. The $275 \mathrm{~cm}^{-1}$ band, superimposed to a broad weak band, is sharp and close to the value recorded for monoclinic $\mathrm{WO}_{3}$, with no real explanation up to now. For $\mathrm{d}-\mathrm{WO}_{3}, \mathrm{a}-\mathrm{WO}_{3}$ and $\mathrm{WO}_{\mathrm{x}}$, a band close to $950-960 \mathrm{~cm}^{-1}$ becomes visible. It is interpreted as $\mathrm{W}=\mathrm{O}$ bond, due to electronic reorganization when 
neighbors are missing at the surface or at the limits of crystallites. A sub trioxide labelled $\mathrm{WO}_{3-\mathrm{x}}$ (possibly $\mathrm{WO}_{2.9}$ according to [57] but it could also be $\mathrm{WO}_{2.72}$ ) and $\mathrm{WO}_{2}$ (formed by heating the $d-W_{3}$ up to $800^{\circ} \mathrm{C}$ in vacuum), are also shown, for comparison. The literature on tungsten nitride is not as rich as the one on oxides, may be due to much fewer applications for nitrides. However, cubic $\mathrm{W}_{2} \mathrm{~N}$, which is supposed to be the most stable phase under normal conditions, is not considered Raman active. When the stoichiometry is not preserved, the $\mathrm{W}$ phonon density of states has been observed to rise close to $200 \mathrm{~cm}^{-1}$, the corresponding bands being roughly ten times more intense than other bands involving $\mathrm{W}-\mathrm{N}$ bonds and lying at $471 \mathrm{~cm}^{-1}$ and in the range $700-800 \mathrm{~cm}^{-1}$ [48]. Then, for an unknown sample possibly containing both $\mathrm{N}$ and $\mathrm{O}$, if bands are observed close to $800 \mathrm{~cm}^{-1}$, they can in principle involve both $\mathrm{W}-\mathrm{N}$ and $\mathrm{W}-\mathrm{O}$ bonds. Depending on the relative amounts of $\mathrm{N}$ and $O$, it can be hard to disentangle the chemical origin of this band. Fortunately, the shape and intensity of the bands below $300 \mathrm{~cm}^{-1}$ behaves differently for oxides and nitrides. For example, the W PDOS is very intense compared to the rest of the bands in the presence of nitrides, which is not the case for oxides.

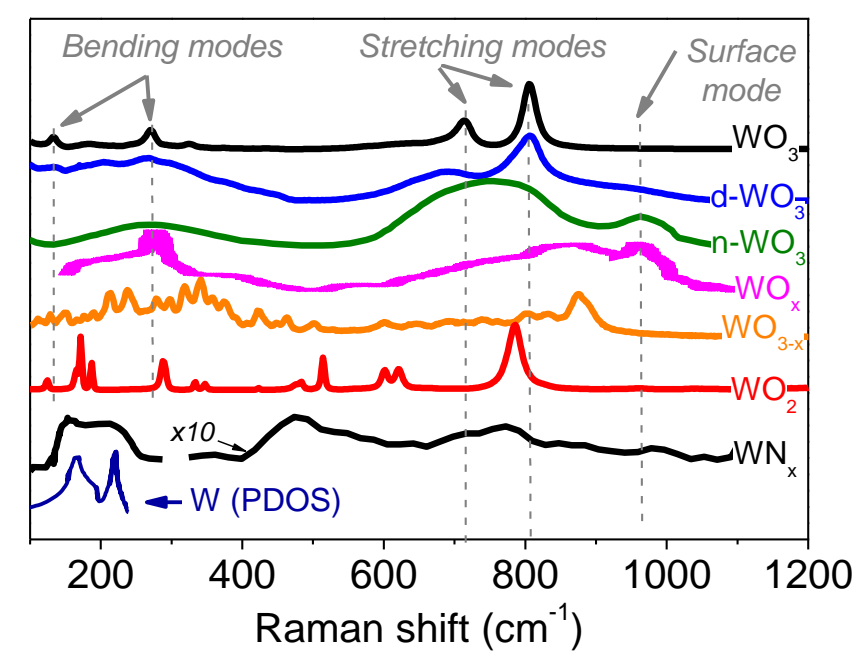

Figure 1. Raman spectra of usual tungsten oxides and nitrides and the $W$ phonon density of states (PDOS) of pure tungsten. Here, $d$ and $n$ stand for defective and nano, respectively. $n$ $W_{3}$ and $W_{x}$ spectra are from [39] and [56], respectively. $W N_{x}$ spectrum is from Ref. [48]. Above $300 \mathrm{~cm}^{-1}$, the intensity has been multiplied by 10 to make the bands visible. W PDOS is from Ref. [58]. 


\section{Results}

The content of impurities ( $\mathrm{O}$ and $\mathrm{N}$ ) is one of the main parameters varied in this study (see table 1). For 0 , it ranges from trace levels when only surface native oxides are formed (the case of $\mathrm{cW}$ sample), up to 75 at. \% in the bulk for $\mathrm{WO}_{3}$ reference layers, with intermediate concentrations varying from 25 to 60 at. \% for the PLD samples. Another parameter to be altered was the morphology of the samples. Raman band intensities have also to be considered in order to obtain information on the $\mathrm{O}$ and the $\mathrm{N}$ contents. Note that this aspect is in general not addressed in the literature as optical properties and electromagnetic wave propagation in the materials need to be precisely known [59], and roughness can play an important role which is difficult to take into account. We present morphology and chemical composition analysis in section 3.1, information retrieved from absolute intensities of oxide related bands in section 3.2 and the effect of the laser beam power in Raman excitations in section 3.3.

\begin{tabular}{|c|c|c|}
\hline Sample & Synthesis method & $\begin{array}{l}\text { Elemental } \\
\text { composition }\end{array}$ \\
\hline cW bulk & From A.L.M.T & $\begin{array}{c}\text { O 0\%, N } 0 \% \\
\text { (purity: } 99.9999 \text { wt\%) }\end{array}$ \\
\hline$c W O(25,2)$ & $\begin{array}{c}P L D \\
(\mathrm{He}, P=70 \mathrm{~Pa})\end{array}$ & $\begin{array}{c}\text { O 25\%, N 2\%, H } 2 \% \\
\text { (TOF ERDA) }\end{array}$ \\
\hline$c \mathrm{WN}(0,20)$ & $\begin{array}{c}P L D \\
(N, P=2.5 P a)\end{array}$ & $\begin{array}{l}O 0 \%, N 20 \% \\
(E D X)\end{array}$ \\
\hline cWON $(37,16)$ & $\begin{array}{c}P L D \\
(\mathrm{He} 90 \%+N 10 \%, P=55 \mathrm{~Pa})\end{array}$ & $\begin{array}{c}\text { O 37\%, N 16\%, H 8\% } \\
\text { (TOF ERDA) }\end{array}$ \\
\hline $\operatorname{cWON}(20,35)$ & $\begin{array}{c}P L D \\
(N, P=20 P a)\end{array}$ & $\begin{array}{c}O 20 \%, N 35 \% \\
(E D X)\end{array}$ \\
\hline$p \mathrm{WO}(60,2.5)$ & $\begin{array}{c}P L D \\
(A r, P=50 P a)\end{array}$ & $\begin{array}{c}\text { O 60\%, N 2.5\%, H 15\% } \\
\text { (TOF ERDA) }\end{array}$ \\
\hline$p \mathrm{WO}(52,4)$ & $\begin{array}{c}P L D \\
(\operatorname{Ar} 97 \%+D 3 \%, P=50 P a)\end{array}$ & $\begin{array}{l}\text { O 52\%, N 4\%, H } 19 \% \\
\text { (TOF ERDA) }\end{array}$ \\
\hline$p \mathrm{WON}(53,12)$ & $\begin{array}{c}P L D \\
(\operatorname{Ar} 97 \%+N 3 \%, P=50 P a)\end{array}$ & $\begin{array}{c}\text { O 53\%, N 12\%, H 19\% } \\
\text { (TOF ERDA) }\end{array}$ \\
\hline$p \mathrm{WON}(47,9)$ & $\begin{array}{c}P L D \\
(\operatorname{Ar} 94 \%+N 3 \%+D 3 \%, P=50 P a)\end{array}$ & $\begin{array}{c}\text { O 47\%, N 9\%, H 24\% } \\
\text { (TOF ERDA) }\end{array}$ \\
\hline$p \mathrm{WON}(20,35)$ & $\begin{array}{c}P L D \\
(N, P=40 P a)\end{array}$ & $\begin{array}{c}O 20 \%, N 35 \% \\
(E D X)\end{array}$ \\
\hline NP-W & $D C$ argon glow discharge & - \\
\hline $\begin{array}{l}\mathrm{WO}_{3} \text { on } \mathrm{W} \\
(20-200 \mathrm{~nm})\end{array}$ & $\begin{array}{c}\text { Thermal oxidation at } 400^{\circ} \mathrm{C}[35] \\
\left(\mathrm{O}_{2} \text { partial pressure: from } 0.7 \text { to } 79 \mathrm{kPa}\right)\end{array}$ & - \\
\hline
\end{tabular}


Table 1. Sample description. Names starting with $c(p)$ correspond to a compact (porous) morphology, as observed by electron microscopy. The first number in parenthesis is the $O$ content and the second is the $N$ content, expressed in atomic percentage.

\subsection{Morphology and chemical composition}
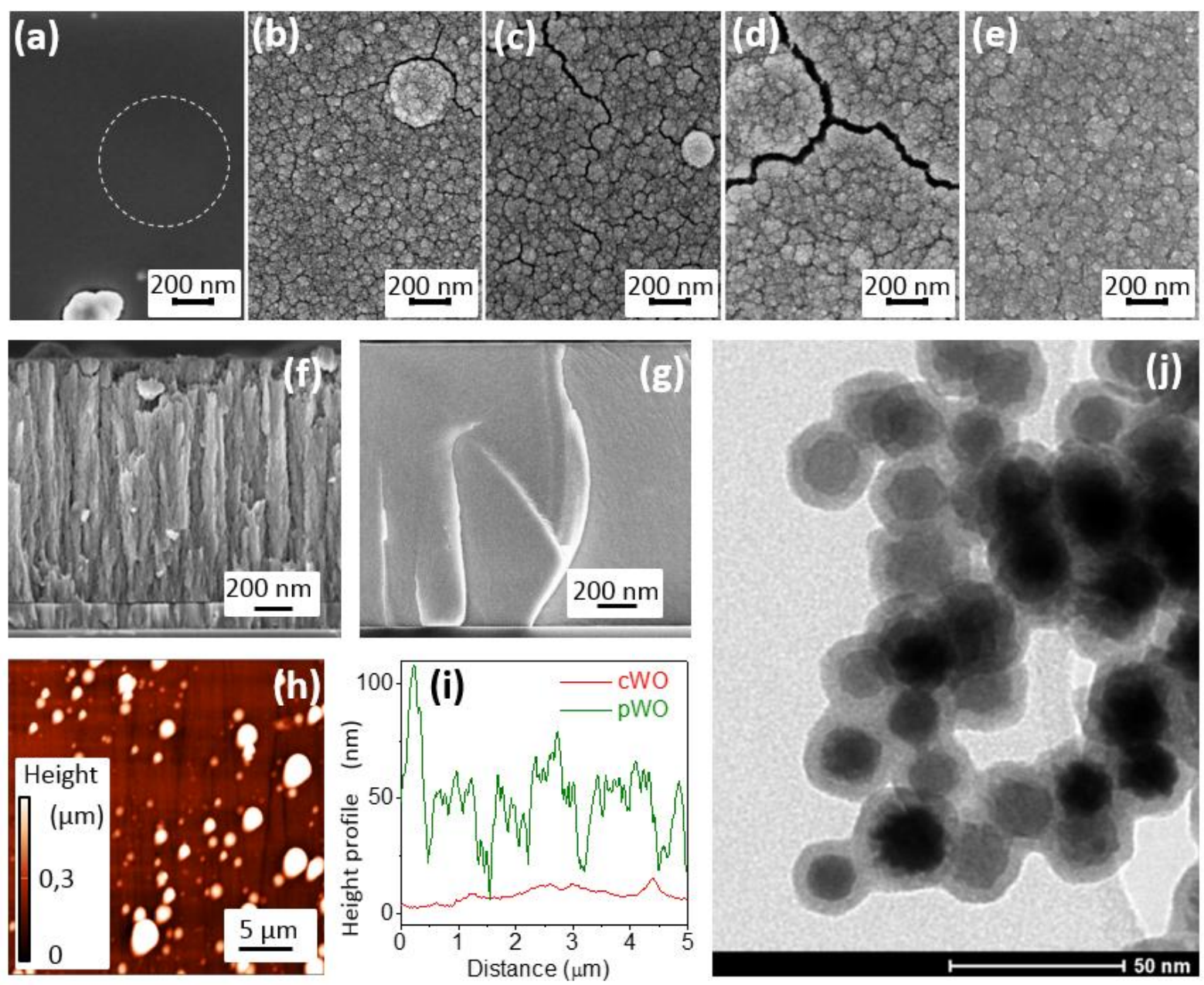

Figure 2. Morphology of the PLD films and the nanoparticles. (a-e) PLD films top view, the dashed white circle represents the size of the laser beam used in the Raman experiments when using an objective with N.A.=0.9. From a to e: $c W O(25,2), p W O(60,2.5), p W O(52,4)$, pWON $(53,12)$ and pWON $(47,9)$. (f, g) Typical SEM cross section view of PLD films, porous (f) and compact (g). (h) Typical AFM top view of porous films. (i) Typical AFM profiles of porous and compact films. (j) Nanoparticles.

Figure 2 shows SEM and AFM images of the PLD films and TEM images of the nanoparticles (NP). Top views of PLD films, cWO(25,2), pWO(60,2.5), pWO(52,4), $p W O N(53,12)$ and $p$ WON $(47,9)$ can be seen in Fig-1 a to e, respectively. Typical porous and 
compact film SEM cross sections (obtained after cleaving the samples) are displayed in figure 1-f and g, respectively. A $30 \times 30 \mu \mathrm{m}^{2}$ AFM image of a typical porous film is displayed in Fig. 1$h$ and typical height profiles of porous and compact films are given in Fig. 1-i. A TEM image of nanoparticles is shown in Fig. 1-j, which reveals a core-shell structure. From figure 1-a to e, one can observe that the morphology of the cWO film is different from that of porous films: the $p \mathrm{WO}(60,2.5), p \mathrm{WO}(52,4), p \mathrm{WON}(53,12)$ and $p \mathrm{WON}(47,9)$ films show a cauliflower-like feature whereas the surface of the $c W O(25,2)$ film is flat and smooth. This morphology is directly related to growth mechanisms [60] governed by the expansion dynamics of the plasma plume during deposition, as discussed elsewhere $[42,43]$. Some cracks are present on the porous films. Cross sections are shown in figures 1-f and g, showing the $1 \mu \mathrm{m}$ thickness of the films. Columnar structures are better visible, at the origin of the porous label of the $p \mathrm{WO}(60,2.5), p \mathrm{WO}(52,4), p \mathrm{WON}(53,12)$ and $p \mathrm{WON}(47,9)$ films. AFM measurements confirm the rough morphology of the porous films $(\approx 25 \mathrm{~nm}$ amplitude obtained on profiles by measuring the peak to peak height) compared to that of the compact samples $(\approx 7 \mathrm{~nm}$ ). Some columns higher than the mean surface by $\approx 200-300 \mathrm{~nm}$ can be seen in Fig 1-b (top right part), $\mathrm{f}$ and $\mathrm{h}$ (white spots are not due to dust). Raman spectra were not acquired on these columns to avoid probing non-representative locations. As reported in $[42,46]$ both $c W O$ and the different $p W O$ and $p W O N$ films exhibit a nanocrystalline structure where the crystallite domains range between 4 and $7 \mathrm{~nm}$. Nanoparticles (Fig 1-j) display a polyhedral form, sometimes nearly spherical, with diameters $\approx 14-20 \mathrm{~nm}$ and a core composed of $W$ in the $\beta$ phase [41], and an oxide shell with a thickness of $\approx 4-5 \mathrm{~nm}$.

XPS spectra of selected W, WN, compact WO, porous WO samples are shown in figure 3-a and $b$ (XPS was not possible for NP as there was not enough material). Their Raman spectra are given in figure 3-c. The XPS spectra recorded in the $4 \mathrm{f}$ region are reported in figure 3-a for bulk oxide samples $\left(\mathrm{d}-\mathrm{WO}_{3}, \mathrm{pWO}(60,2.5)\right.$ and $\left.\mathrm{cW}(25,2)\right)$ and in figure 3-b for surface oxides $(c W)$ and for nitrides $(c W N(0,20))$. According to the 2012 update of the NIST database [61] $4 f_{7 / 2}$ and $4 f_{5 / 2}$ lie at $31 \mathrm{eV}$ and $33 \mathrm{eV}$, respectively for $\mathrm{W}$ [62] whereas they lie at around 36 and $37.5 \mathrm{eV}$ for $\mathrm{WO}_{3}[62,63]$. An additional shift of roughly $0.5 \mathrm{eV}$ has been reported in the literature [53], possibly due to nano structuration and phase changes; we do not discuss in this publication. The XPS spectrum of $\mathrm{d}-\mathrm{WO}_{3}$, extracted from [37], is composed of two peaks related to $\mathrm{WO}_{3}$ but slightly shifted (it can be due to a variation of the work function between the different samples or setup calibration). The XPS spectra of $p$ WO 
samples display mainly two peaks at 36 and $37.5 \mathrm{eV}$, originating from oxide formation but are broader and more overlapped compared to those of $d-W_{3}$. A weak peak observed at $30.8 \mathrm{eV}$ for $p \mathrm{WO}$ is due to bulk W. Such measurement is consistent with the stoichiometry measured by TOF-ERDA. The XPS spectra of $c$ WO samples shows a combination of oxide and W components, meaning coexistence of an oxide phase and a $W$ phase, in different proportion than for $p$ WO samples, still consistent with TOF-ERDA measurements. For samples supposed to have no oxide in the bulk, XPS spectra are shown in figure 3-b. The XPS spectrum of the $\mathrm{cW}$ sample is composed of 2 intense peaks lying at 31 and $33 \mathrm{eV}$ plus two weaker peaks at 35 and $37.5 \mathrm{eV}$. These indicate a low amount of oxide at the surface of the film (here, XPS roughly probes a depth of $1.5 \mathrm{~nm}$ ). The XPS spectrum of the $\operatorname{cWN}(0,20)$ sample is composed of 4 broad overlapping peaks, situated approximately where WO and W signals are expected. Some studies suggest that WN signals are in the range 31.5-31.7 eV [64] whereas others mention 32.6 and $34.7 \mathrm{eV}$ [65]. One must note that the most intense peaks in figure 3.b are the 35.7 and $33.7 \mathrm{eV}$, close to where WN should fall according to [65]. In any case, the WN signal overlaps with $\mathrm{W}$ and WO signals, and the shown spectrum corresponds to a mixture of $\mathrm{W}, \mathrm{WN}$ and $\mathrm{WO}$. It reveals that the $c \mathrm{WN}$ film is oxidized within the probed XPS depth range, in a much larger extent than the $c W$ film. Note that the oxidation levels can also affect the global shape of the XPS spectra: for example $\mathrm{W}^{4+}$ are close to $4 f_{5 / 2}$ and $4 f_{7 / 2}$ related to $W$, and $W^{5+}$ are in between $4 f_{5 / 2}$ and $4 f_{7 / 2}$ related to $W O_{3}$ [37], and fitting with the resolution used will not allow quantitative results.

In figure 3-c, the Raman spectrum recorded for the $c \mathrm{~W}$ sample display bands lie in the bending $\left(300 \mathrm{~cm}^{-1}\right)$ and stretching $\left(700-800 \mathrm{~cm}^{-1}\right)$ spectral regions, confirming the presence of oxide. There is also an extra surface band $\left(950 \mathrm{~cm}^{-1}\right)$ which is very intense, proving the presence of defective $\mathrm{W}=\mathrm{O}$ bonds. In $\mathrm{W}$ crystals, the penetration depth of visible light is supposed to be only a few tens of $n m$ due to the metallic nature of $W$ [66]. Therefore, the origin of this band is from $\mathrm{W}-\mathrm{O}$ bonds close to the surface, formed due to the exposure to air. Comparison with other materials $(p \mathrm{WO}(60,2.5), c \mathrm{WO}(25,2), c \mathrm{WN}(0,20), \mathrm{NP}$ and defective $\mathrm{WO}_{3}$ ) is done in this figure. Both $p \mathrm{WO}$ and NP display an intense $950 \mathrm{~cm}^{-1}$ band, showing the existence of a large amount of surface area in these samples, in agreement with what is seen by electron microscopy in figure 2 for $p$ WO (Fig. 2 f) and NP (Fig. 2 j) samples. For the $\mathrm{cW}$ sample, the $950 \mathrm{~cm}^{-1}$ band is observed as well, proving that a large surface is present too. For cW, extra well-defined bands are observed close to 400 and $650 \mathrm{~cm}^{-1}$. 
According to ultra-high vacuum experiments, vibrational modes of $\mathrm{O}$ adsorbed on top of W(110) for high surface coverage (750 ML) [67] lie at 428 and $657 \mathrm{~cm}^{-1}$. These observations suggest that two contributions leading to WO bonds exist for the $\mathrm{cW}$ sample: $\mathrm{O}$ adsorbed on the $\mathrm{W}$ surface and $\mathrm{WO}$ bonds organized as small $\mathrm{WO}_{3}$ crystals, leading to a large amount of crystallite surface sites. Note that the features appearing in the dashed rectangle of figure 3c are not attributed to the samples but to experimental conditions taking into account the nature of the used lens, time acquisition and incident angle [68].
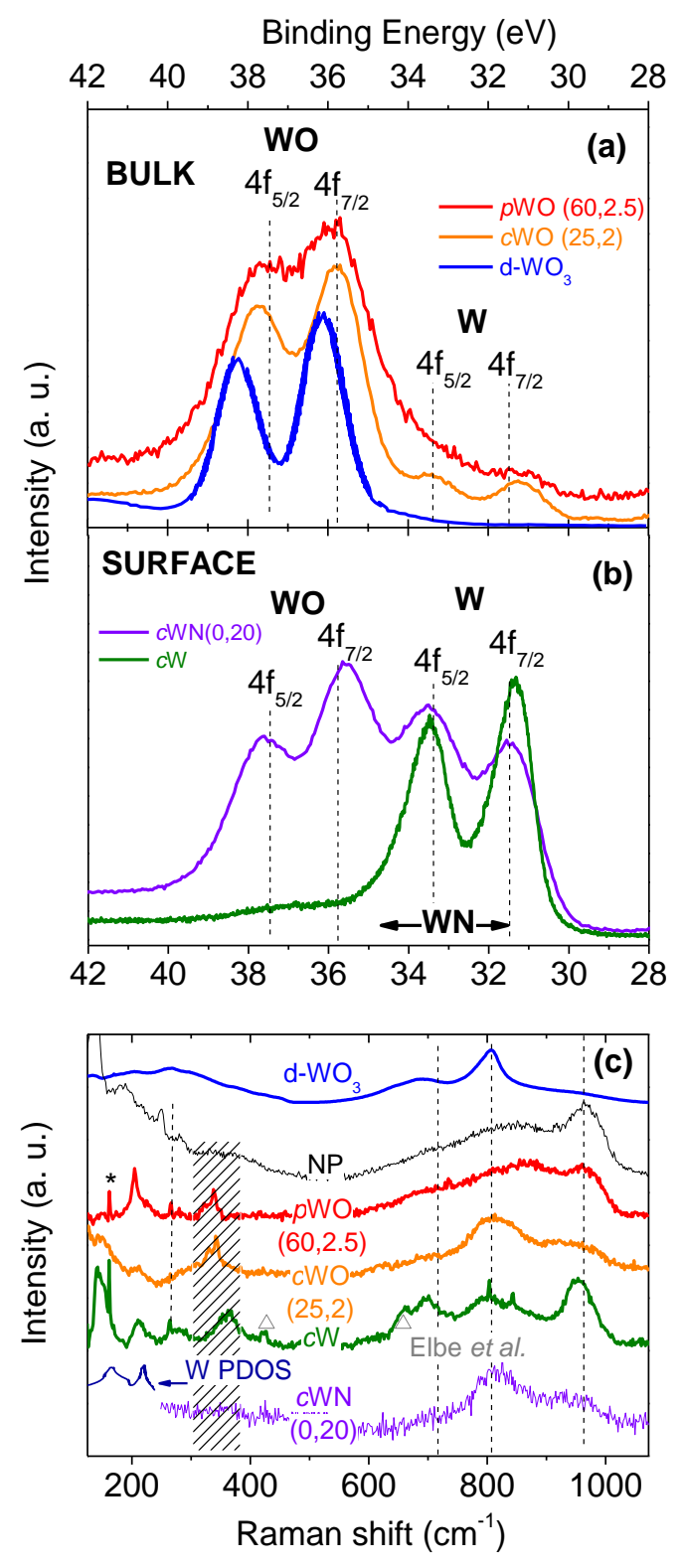

Figure 3. XPS and Raman spectra of $d-W O_{3}, N P, p W O, c W O, c W$ and $c W N$ samples. XPS spectra of (a) pWO(60, 2.5), cWO(25,2) and d-WO 3 (the latter from [37]) and (b) $c W N(0,20)$ and $\mathrm{cW}$. (c) Raman spectra. The dashed rectangle of figure 3-c is not attributed to the 
samples but to the experimental conditions taking into account the nature of the used lens, time acquisition and incident angle [68]

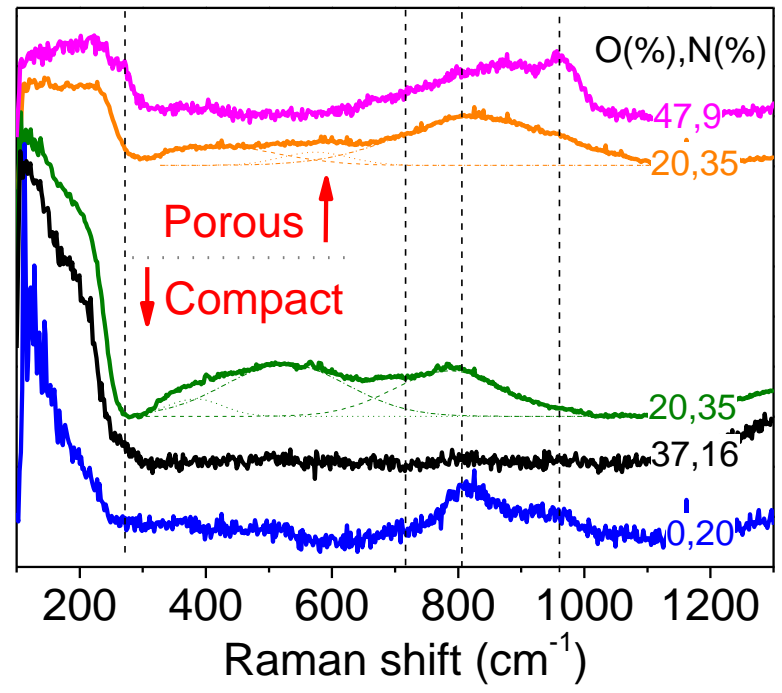

Figure 4. Comparison of the Raman spectra of $N$ containing films.

Figure 4 shows normalized Raman spectra of different WON samples, either compact or porous. The first observation is that porous and compact samples behave differently and the weight of the W PDOS (below $300 \mathrm{~cm}^{-1}$ ) compared to the $\mathrm{O}$ - or N-related bands at higher wavenumbers is much higher for compact samples than for porous samples. A second observation concerns the surface $\mathrm{W}=0$ band at $950 \mathrm{~cm}^{-1}$. The $p \mathrm{WON}(47,9)$ spectrum is similar to that of $\mathrm{WO}_{\mathrm{x}}$ with a strong contribution of this band: the amount of $\mathrm{O}$ is much more important than the amount of $\mathrm{N}$, and in addition nitrides are not supposed to be Raman active. Thus, for low $\mathrm{N}$ concentrations, oxygen governs the overall Raman spectral shape in the $300-1000 \mathrm{~cm}^{-1}$ spectral region. However, the shape of the bands below $300 \mathrm{~cm}^{-1}$ behaves differently than for $\mathrm{WO}_{\mathrm{x}}$, which could be due to the presence of $\mathrm{N}$ (activating W PDOS), as discussed in section 2.3. When the N/O ratio increases, the behavior changes. For example, $p$ WON $(20,35)$ is composed of three broad overlapping gaussians profiles in the range 300 $1000 \mathrm{~cm}^{-1}$. The main one is centered at $833 \mathrm{~cm}^{-1}$, whereas the others are centered at 417 and $573 \mathrm{~cm}^{-1}$. The first band is interpreted as being partly due to $\mathrm{W}-\mathrm{N}$ and $\mathrm{W}-\mathrm{O}$ bonds, because of its position close to both $\mathrm{W}-\mathrm{N}$ and $\mathrm{W}-\mathrm{O}$ stretching mode bands, according to figure 1, whereas the two other bands are due to $\mathrm{W}-\mathrm{N}$ bonds. For the compact $\operatorname{cWON}(20,35)$ 
sample, the $300-1000 \mathrm{~cm}^{-1}$ spectral range is also composed of three broad overlapping bands attributed to $\mathrm{W}-\mathrm{N}$. But this is not the case for all the N/O ratios. Pure nitrogen doped tungsten, the $c W N$ sample, display bands at 813 and $950 \mathrm{~cm}^{-1}$, in addition to weaker features around $400 \mathrm{~cm}^{-1}$ (broad features between 300 and $550 \mathrm{~cm}^{-1}$ ). The 813 and $950 \mathrm{~cm}^{-1}$ bands are interpreted as originating from octahedra and from surface $\mathrm{W}=\mathrm{O}$ bonds, respectively. The $\mathrm{W}-\mathrm{N}$ bonds could be related to the very weak signal around $400 \mathrm{~cm}^{-1}$. The spectrum from the $\operatorname{cWON}(37,16)$ sample is totally flat in the same spectral region. In this case, the absence of bands whereas $\mathrm{W}-\mathrm{N}$ bonds are present in $\operatorname{cWON}(37,16)$ can be due to some quantum-selection rules related to the structure during the Raman scattering process, whereas the presence of defects (like oxygen and nitrogen, grain boundaries due to small crystallite size,...) can break the related quantum selection rules, leading to the presence of these bands. The lack of signal intensity corresponding to $\mathrm{W}-\mathrm{O}$ bonds is different here, possibly due to the stability of the $\mathrm{W}-\mathrm{N}$ bonds that hinder the formation of $\mathrm{W}-\mathrm{O}$ bonds during the deposition process of the film. This point will be addressed in section 3.2.

To briefly summarize the findings reported above that concern Raman spectroscopy measurements:

- oxides have been detected on a compact W sample, likely due to native oxides (see section 3.2 for sensitivity discussion)

- Compact and porous PLD films exhibit Raman spectra that are distinguishable

- Spectra of porous films and oxides found on nanoparticles are similar, displaying a mode related to surface bonds, lying at $960 \mathrm{~cm}^{-1}$

- $\quad \mathrm{N}$ content does not lead to strong specific bands but to low frequency modes which are related to the PDOS of W, as found for mixed W:Be deposits [69].

- For some concentrations, oxides are no more observed on W/O/N samples, that could mean the presence of substituting $\mathrm{N}$

\subsection{Information retrieved from Raman absolute band intensities}

While we have discussed information retrieved from the spectral shape, band positions and relative intensities, and the ways to distinguish the presence of $\mathrm{N}$ when the sample contains also oxygen, we now discuss the information retrieved from absolute band intensities and its relation to the sample composition. Absolute band intensities are here referred to the height of the band normalized by the height of the band at $520 \mathrm{~cm}^{-1}, \mathrm{H}_{\mathrm{Si}}$, of a 
silicon crystal measured in the same experimental conditions, as this intense band is often used as a reference [40].

In figure 5, the height of the band at $800 \mathrm{~cm}^{-1}, \mathrm{H}_{800}$, is taken on the rough spectra, i.e. without band fitting, and after base line subtraction. The height ratio, $\mathrm{H}_{800} / \mathrm{H}_{s i}$ is shown in figure 5-a as a function of the oxygen atomic fraction. A general tendency is that the more oxygen the material contains, the more intense the $800 \mathrm{~cm}^{-1}$ band, approximately following an exponential law (the dashed line is a guide for the eyes). This trend is well followed for samples that have a similar porous morphology: $p \mathrm{WO}(60,2.5), p \mathrm{WO}(52,4), p \mathrm{WON}(47,9)$, and $p W O N(53,12)$ and for which nitrogen is not the dominant impurity element. For nanoparticles, the $\mathrm{H}_{800} / \mathrm{H}_{\mathrm{Si}}$ ratio equals 0.12 , the highest value recorded in this study. The intersection between the dashed line and this value is at $63 \%$ of oxygen. This value is close to the fraction of oxides that can be estimated from TEM images for an average nanoparticle. This indicates that the empirical exponential behavior works qualitatively well for this sample too. When the nitrogen content increases a little, here for the $p \operatorname{WON}(53,12)$ sample, data are still close to the dashed line, however slightly up-shifted. The shift becomes very large for the high N/O ratio of the $p \mathrm{WON}(20,35)$ data. Note that this data point could be moved a bit closer to the dashed line if one replaces the $x$-axis, which is the fraction of oxygen $\mathrm{O}(\%)$, by $\mathrm{O}(\%) \times 100 /(100-\mathrm{N}(\%))$, which represents the fraction of $\mathrm{O}$ bonded to $\mathrm{W}$, excluding the overall tungsten content the ones bonded to $\mathrm{N}$. This transformation is shown in figure 5-b. By doing that, one assumes that $\mathrm{W}-\mathrm{N}$ bonds do not participate significantly to the intensity of the band close to $800 \mathrm{~cm}^{-1}$. Another hypothesis is that $\mathrm{O}$ and $\mathrm{N}$ are not bonded together but only to $\mathrm{W}$. If this was not the case, it would shift horizontally the experimental point in figure 5-b. However, the operation that allows to jump from figure 5-a to $b$ is not $100 \%$ satisfactory as all the corresponding data do not align well on the dashed line. Some other parameters, difficult to take into account (and out of the scope of this study) can also influence band intensities and explain some behaviors. First, the optical constants of the sample (real and imaginary parts of the refractive index, $n$ and $k$, respectively) which depends on the chemical composition, drive the light propagation. According to [70], tungsten oxides with $O$ content higher than $\approx 73 \%$ behaves as a dielectrics whereas for concentrations lower than $73 \%$ the sample behaves as a metal. According to [71], tungsten nitrides are good absorbers but with $k$ values which can be $\approx 60 \%$ lower than the corresponding value for tungsten. To our best knowledge, nothing is documented on the 
optical constants of mixed WON samples. However one can imagine that if the $k$ value is lower for $p \mathrm{WON}(20,35)$ than for the samples aligned on the dashed line: light then probes deeper the sample, thus increasing the intensity of the $800 \mathrm{~cm}^{-1}$ band, which could explain part of the deviation from the empirical relation. Another parameter that influences band intensities is surface roughness. For conducting media like $W$, light penetrates only on a few tens of $\mathrm{nm}$. The scattering process is then very sensitive to the surface structure and an increase of Raman intensities is expected in case of roughness. Here, the roughness is in the range from a few $\mathrm{nm}$ to a few tens of $\mathrm{nm}$, as can be seen in figure 2-i and this likely explains the $\mathrm{H}_{800} / \mathrm{H}_{\mathrm{Si}}$ ratio increase (one order of magnitude) from compact $c \mathrm{WON}(20,35)$ to porous $p \mathrm{WON}(20,35)$, both having the same chemical composition.

Focusing now on the compact samples, one can see that except for $c \mathrm{WO}(25,2)$, they all have a lower band intensity than porous samples. For $c \mathrm{~W}$, tungsten oxide comes from native oxide and the $\mathrm{H}_{800} / \mathrm{H}_{\text {si }}$ value is representative of WO bonds close to the surface. XPS measurements done after heating the sample to $700^{\circ} \mathrm{C}$ under UHV conditions allowed us to obtain the atomic composition from relative intensities of $\mathrm{W}$ and WO peaks: $21.9 \%$ oxygen content in the surface layer, being close to a $\mathrm{W}_{3} \mathrm{O}$ stoichiometry [72]. The oxygen content was estimated by performing Angle-resolved XPS experiments. The emission angle at which the electrons were collected was varied from 0 to 30 degrees (with respect to the normal), thereby enabling electron detection from different material depths. Raman data were recorded in air only a couple of hours after the XPS measurement. The Raman spectrum (see figure 3-a) suggests a $\mathrm{WO}_{6}$ octahedral symmetry as discussed above and gives a value of $\mathrm{H}_{800} / \mathrm{H}_{\mathrm{Si}}=0.0027$, which may involve a low oxide thickness. Some comments about oxide thickness are given later in the article, in connection with figure 5 -c. The $c \mathrm{WN}(0,20)$ sample contains no oxygen in the bulk. The $800 \mathrm{~cm}^{-1}$ band of its Raman spectra, which originates from $\mathrm{W}-\mathrm{O}$ bonds is then related to the surface. Its intensity is lower than the one of $\mathrm{cW}$ because not all the tungsten atoms close to the surface are free to bond with surface oxygen but are instead involved in $\mathrm{W}-\mathrm{N}$ bonds. This is even more pronounced for $\operatorname{cWON}(37,16)$ where no band at $800 \mathrm{~cm}^{-1}$ was detected. According to the empirical law, $\mathrm{H}_{800} / \mathrm{H}_{\mathrm{Si}}$ should be close to 0.01 , whereas our analyses bring it lower than 0.0001 . This discrepancy could be due to a crystallographic structure that is different from the other samples, leading to no Raman active modes in that spectral region, highlighting the fact that the atomic structure could play a huge role. The $c \operatorname{WON}(20,35)$ sample is slightly out of the dashed line but the data 
point can be brought closer to the line on if one does the same treatment as for $p$ WON $(20,35)$, replacing $\mathrm{O}(\%)$ by $\mathrm{O}(\%) \times 100 /(100-\mathrm{N}(\%))$ (i.e. changing from figure 5 -a to figure $5-b)$. However, the $\mathrm{cWO}(25,2)$ sample is found one order of magnitude more intense than what suggests the empirical law determined from other samples with similar oxygen content. We believe this is an anomaly caused by the delay between the production, measurement of the oxygen content (one year later) and the Raman measurements of particular samples. Contrary to porous samples, which can develop rapidly an oxide layer with a saturating thickness, more time is needed for bulk materials to reach a saturating oxide layer thickness that acts as a barrier to oxygen diffusion. More detailed kinetic studies are therefore needed to control this phenomenon, which is critical for the future analysis of PFC that will be stored for long period before analysis during a post-mortem analysis phase.

In figure 5-c, we investigate the role of optical constants on the $800 \mathrm{~cm}^{-1}$ band intensity, with the help of a simple model developed originally for graphene [73]. The model that gives an enhancement factor has been scaled to reproduce experimental data. It calculates the influence on the Raman band intensities of a layer deposited on top of a semiinfinite media. Multi reflections are then considered in the calculation. Figure 5-c display Raman intensities of $\mathrm{WO}_{3}$ layers, with thicknesses ranging from 20 to $200 \mathrm{~nm}$ and grown under controlled conditions (see [35] for details). The measured $\mathrm{H}_{800} / \mathrm{H}_{\mathrm{Si}}$ varies from $\approx 0.1$ to $\approx 1$, which is one to two decades higher than for the samples discussed previously, which were found in the range $\approx 0.001$ to $\approx 0.16$. Calculations with several optical constants ( $\mathrm{n}$ and k) have been done in the range 1-300 $\mathrm{nm}$. Pure oxide is supposed to be $n=2.2$ and $k=0$ for $\lambda_{L}=514 \mathrm{~nm}$. Introducing some disorder can slightly diminish $\mathrm{n}$, and increase $\mathrm{k}$, the material thus becoming more absorbing. For pure metallic $W$, the optical constants are $n=1.8$ and $k=4.9[74,75]$. The first calculation ( $n=2, k=0-n o$ absorption) reproduces well the experimental data. Extrapolation for intensities in the range close to the one of $c \mathrm{~W}$ leads to a thickness of $\approx 5 \mathrm{~nm}$. Diminishing $\mathrm{n}$ and increasing $\mathrm{k}$, which can simulate $\mathrm{O}$ and/or $\mathrm{N}$ content changes [70,71], does not change the global shape of the curve below $100 \mathrm{~nm}$. Extrapolation to the $c \mathrm{~W}$ thickness now gives a smaller value of $\approx 3 \mathrm{~nm}$. One conclusion is that such calculations can be used to deduce thicknesses, but it leads to quite large uncertainty as optical constants are not well known. In our case, the conclusion is that for $\mathrm{cW}$, native oxide layer thickness is in the range $\approx 3-5 \mathrm{~nm}$. For $c \mathrm{WO}(25,2)$, if one supposes native oxide 
behaves as a bulk oxide from an optical property point of view, one obtains a thickness of $\approx$ $12 \mathrm{~nm}$, which is compatible with a slow growth of native oxide during the one year period discussed above. For porous materials, roughness must be taken into account and thicknesses cannot be retrieved from this simple model.
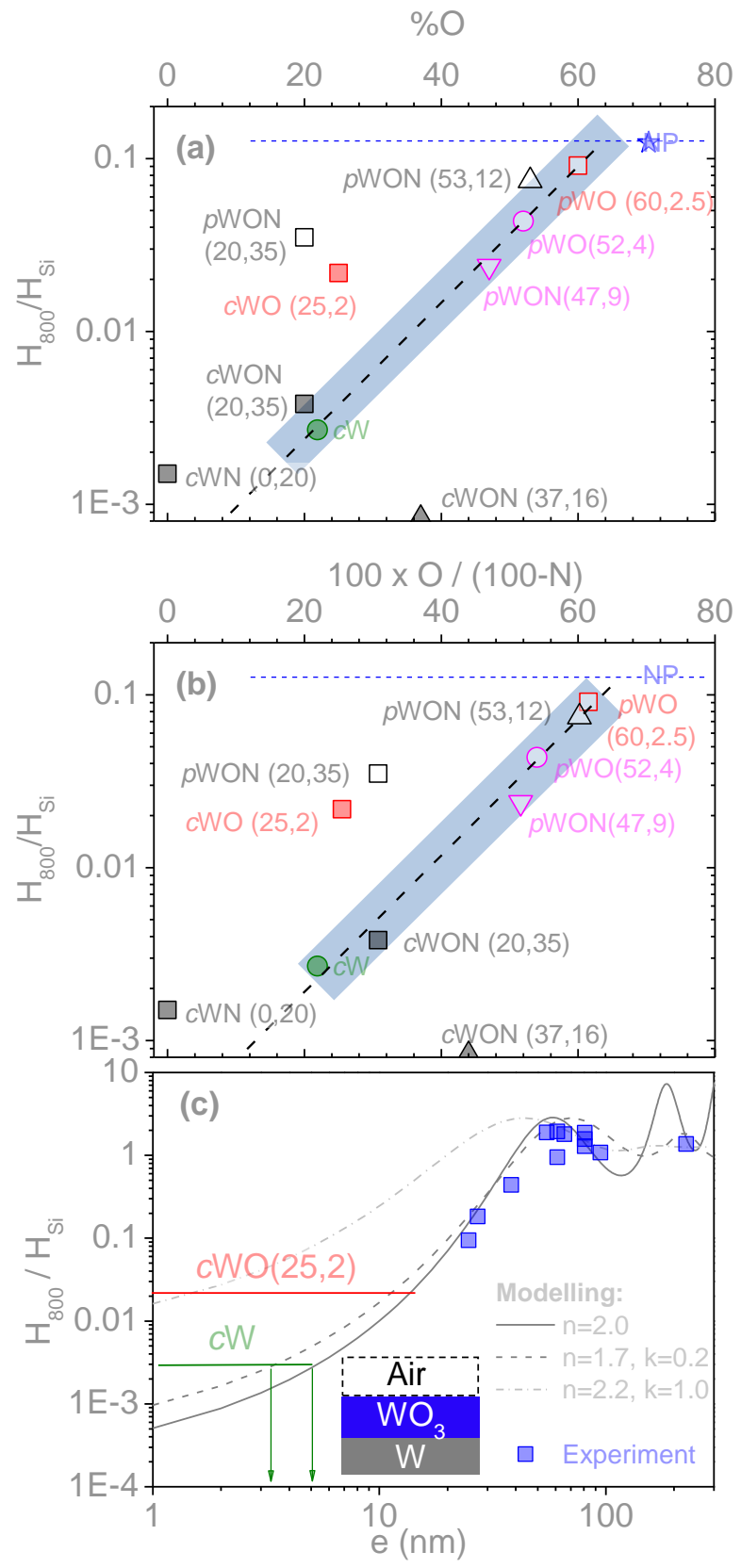

Figure 5. Raman band intensity evolution with respect to the oxygen content. (a) $H_{800} / H_{s i}$ as a function of the $O$ content (the dashed line is a guide for the eyes). (b) Same, but as a function of $100 \times 0 /(100-N)$. In (a) and (b), the dotted blue line represents the nanoparticles value, for comparison. (c) Evolution of $\mathrm{H}_{800} / \mathrm{H}_{s i}$ for $d-\mathrm{WO}_{3}$ layers as a function of film thickness. The 
curve represents calculations for different optical indexes. Horizontal lines are experimental values of $\mathrm{H}_{800} / \mathrm{H}_{S i}$ for $\mathrm{cWO}(25,2)$ and $\mathrm{cW}$.

\subsection{Laser heating as complementary diagnostic: $\mathrm{O} / \mathrm{N}$ substitution}

As shown in the previous section, compact or porous characteristics can play an important role in the amount of oxides in the material. We address here the question of whether or not oxidation can be induced by local heating due to the Raman laser beam as measurements are performed under ambient atmosphere. We propose below a methodology involving a power variation of the laser intensity up to four orders of magnitude.
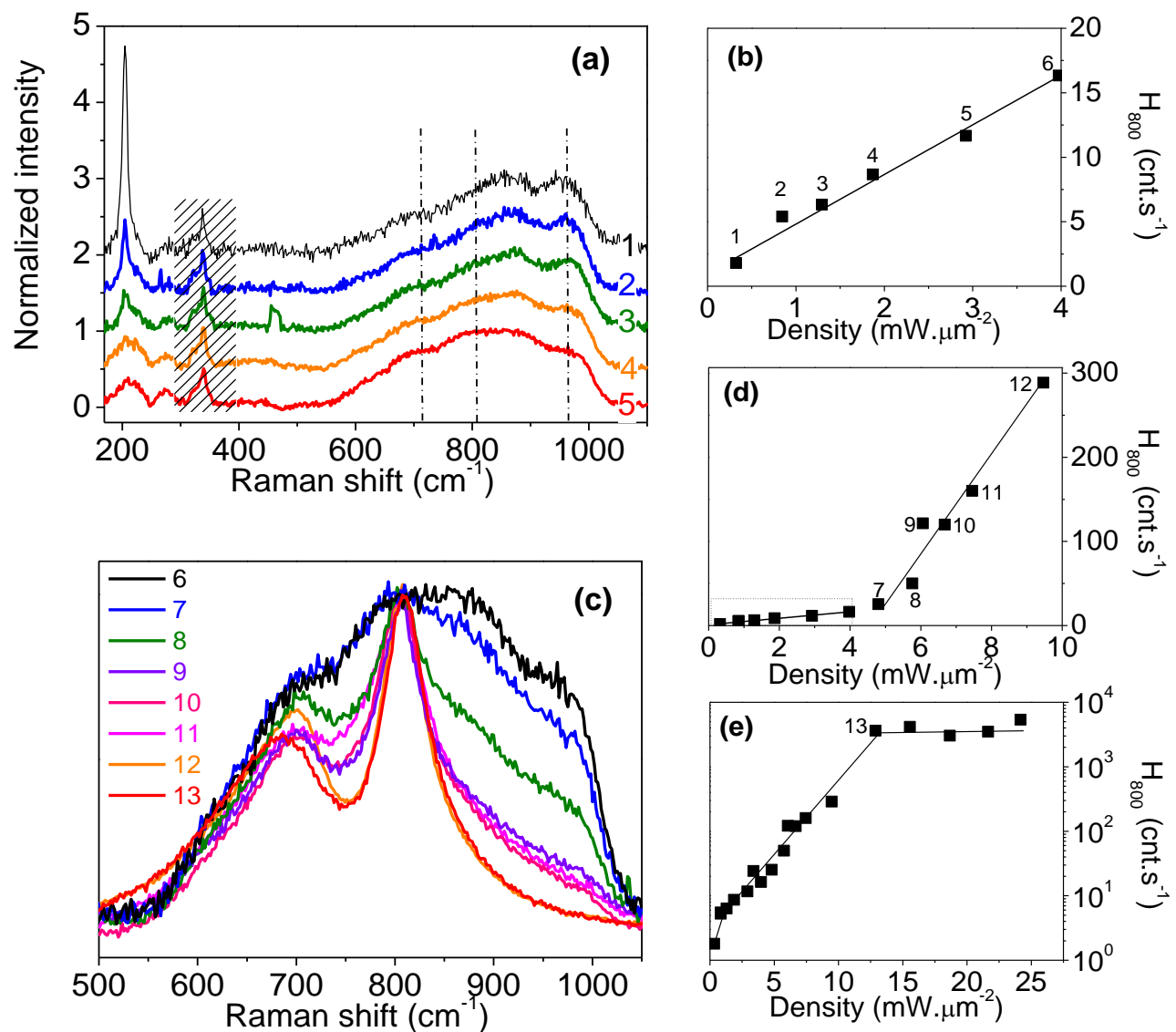

Figure 6. Influence of laser power density on the $p W O(60,2.5)$ sample. (a) Normalized spectra (vertically shifted for clarity) and (b) $800 \mathrm{~cm}^{-1}$ band height $\left(H_{800}\right)$ as a function of power 
density (from 0.3 to $4 \mathrm{~mW} \cdot \mu \mathrm{m}^{-2}$ ). (c-e) Normalized spectra and $H_{800}$ as a function of power density for power density higher than $4 \mathrm{~mW} . \mu \mathrm{m}^{-2}$. Dashed square of (d) is the range of (b). The density at which the spectra plotted in figure a and $c$ were recorded are given in figure $b$, $d$ and $e$.

Figure 6 shows the evolution of Raman spectra of the $p \mathrm{WO}(60,2.5)$ sample under different power laser conditions. The spectra in figure 6-a and 6-c are normalized to the height at $800 \mathrm{~cm}^{-1}$ and shifted vertically for clarity. The spectra 1 to 5 (6 to 13) of figure 6-a (6-c) correspond to power density varying from 0.3 to 3 (4 to 10) $\mathrm{mW} . \mu \mathrm{m}^{-2}$. In figure3-a, in the range $500-1100 \mathrm{~cm}^{-1}$, the spectral shape does not evolve, and is composed of three overlapping bands proving the presence of oxides in octahedral forms as discussed in figure 3. For power densities higher than $1.5 \mathrm{~mW} . \mu \mathrm{m}^{-2}$, the band at $950 \mathrm{~cm}^{-1}$ becomes slightly weaker with respect to the band at $800 \mathrm{~cm}^{-1}$, showing that the surface to volume ratio starts to be somewhat modified under the beam. There is a new signature at $205 \mathrm{~cm}^{-1}$ and its relative intensity diminishes when increasing the laser power. This signature will be discussed in figure 7 . The $800 \mathrm{~cm}^{-1}$ band intensity variation with power density is given in figure $6-b$, where $\mathrm{H}_{800}$ evolves linearly as expected since the Raman signal is proportional to the number of incoming photons. When the power is increased beyond $4 \mathrm{~mW} . \mu \mathrm{m}^{-2}$, changes in the $500-1100 \mathrm{~cm}^{-1}$ region become important (figure 6-c): the $950 \mathrm{~cm}^{-1}$ band significantly diminishes compared to the other bands, and the overlap between the bands close to 700 and $800 \mathrm{~cm}^{-1}$ decreases, behaving more and more as an organized phase, resembling $\mathrm{WO}_{3}$ (see figure 1). In figure $6-d$, the $\mathrm{H}_{800}$ versus power density curve increases its slope drastically for power density higher than a threshold of $4 \mathrm{~mW} . \mu \mathrm{m}^{-2}$. Figure 6-e, in semilogarithmic plot on the vertical axis, shows the existence of a saturation regime reached for this sample close to $12 \mathrm{~mW} \cdot \mu \mathrm{m}^{-2}$. These observations indicate that a well-organized $\mathrm{WO}_{3}$ layer is formed under the laser beam and therefore that the temperature is sufficiently high to activate oxidation mechanisms in the presence of $\approx 0.2$ bar of $\mathrm{O}_{2}$ and traces of water (a few hundreds of kelvins according to [55] and references therein. See also the discussion on the last figure of this paper). This is possible only if heat cannot be evacuated by the sample and this principally occurs when the morphology is not optimal for heat dissipation. Then, reaching the laser power density threshold allows atoms to reorganize and change structure. To 
prove this qualitative argument, we show in figure 7 the same kind of graph for the three studied morphologies: compact (figure 7-a), porous (figure 7-b) and nanoparticles (figure 7c). Compact sample spectra do not evolve on the whole range of power density tested here (up to $24.15 \mathrm{~mW} . \mu \mathrm{m}^{-2}$ ), whereas for the porous sample and nanoparticles, the shapes in the $500-1100 \mathrm{~cm}^{-1}$ region (which are similar but with a higher $950 \mathrm{~cm}^{-1}$ band for nanoparticles) change from disordered to a more organized oxide at 4 and $1 \mathrm{~mW} . \mu \mathrm{m}^{-2}$, respectively. The power at which new oxide is created is higher for the porous sample than for nanoparticles, indicating that the porous film can dissipate heat, more efficiently than nanoparticles (which are agglomerated). The Raman spectral shape corresponding to the more organized samples differs in the two cases: it is similar to what is expected for well-organized $\mathrm{WO}_{3}$ in the porous sample whereas for nanoparticles the main signal comes from the band at $950 \mathrm{~cm}^{-1}$. This reveals a phase which has a large surface / volume ratio (with no coalescence of nanoparticles when the power increases). The band observed at $205 \mathrm{~cm}^{-1}$ has already been observed previously and tentatively attributed to the presence of small domains and stoichiometric defects [56]. It is not often reported in the literature and its interpretation is still under debate. We show here that it disappears when the applied laser power density is too high. Note that this band is not observed for compact samples but is observed, although down-shifted by $65 \mathrm{~cm}^{-1}$, for nanoparticles: this indicates that it is related to surface vibrators, confirming the previous interpretation involving small domains and/or defects. 


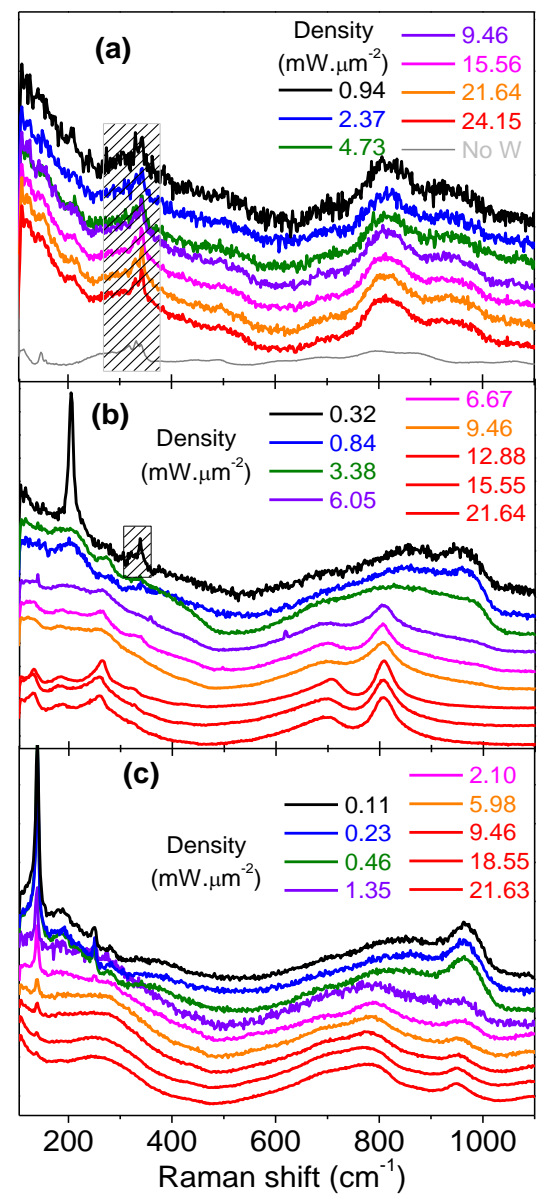

Figure 7. Influence of morphology on sample evolution under laser irradiation. (a) Compact WO, cWO $(25,2)$. (b) Porous WO, pWO(60, 2.5). (c) Nanoparticles.

To systematically investigate the power density at which the laser beam creates oxide, the intensity of the oxide band at $800 \mathrm{~cm}^{-1}$ is compared to that of silicon at $520 \mathrm{~cm}^{-1}$, recorded in the same experimental conditions. If no evolution with power density is expected, then as the band intensities of oxide and silicon are both proportional to the number of incoming photons (and thus to the power density of the used laser beam), $\mathrm{H}_{800} / \mathrm{H}_{\mathrm{Si}}$ should remain constant. On the other hand, if oxides are created, as shown in figure 
6, $\mathrm{H}_{800} / \mathrm{H}_{\mathrm{Si}}$ will evolve with the laser power density. In figure 8 , we plot this ratio for some compact and porous samples as a function of the laser power density, for samples without nitrogen in figure 8-a, and for samples with both oxygen and nitrogen in figure 8-b. Figure 8a shows that, as expected for compact samples, for $c \mathrm{~W}$ and $c \mathrm{WO}(25,2)$, the ratio remains constant within the entire range of investigated power densities (dispersion around this value comes from the size of the spot which could change a little from one measurement to another), meaning the oxides probed by Raman spectroscopy are not created but are inherent to the pristine samples. On the other hand for porous samples and nanoparticles, there is a clear threshold (close to 4 for $p \mathrm{WO}(52,4), p \mathrm{WO}(60,2.5)$ and $1 \mathrm{~mW} \cdot \mu \mathrm{m}^{-2}$ for NP) after which the ratio starts to increase drastically, up to $\mathrm{H}_{800} / \mathrm{H}_{\mathrm{Si}} \approx 5$. According to the model presented in figure $5-\mathrm{c}$, this value corresponds to a thickness of about $50 \mathrm{~nm}$. This is of course a very approximate thickness estimation as the model is based on a simple slab geometry. In reality, samples are porous and the oxide created by the laser beam is almost circular in the $x, y$ plane with a radius close to that of the laser spot, meaning the oxide created is surrounded by porous tungsten containing various amounts of $O$, depending on the sample. On the contrary, figure 8-b shows that, for compact samples, except in the case of $c \mathrm{WN}(0,20)$ which behaves similarly to $c \mathrm{~W}, \operatorname{cWON}(20,35)$ and $c \mathrm{WON}(37,16)$ starts to evolve at a threshold of $\approx 10$ and $8 \mathrm{~mW} . \mu \mathrm{m}^{-2}$, respectively (with no detectable oxide for the latter below this threshold). These results show that the presence of $\mathrm{N}$ likely favor the creation of oxides in compact layers. On the other hand, the three porous samples ( $p \operatorname{WON}(53,12)$, $p \mathrm{WON}(47,9)$ and $p \mathrm{WON}(20,35))$ behave more or less similarly to each other and to the one without $\mathrm{N}$ : the $\mathrm{H}_{800} / \mathrm{H}_{\mathrm{Si}}$ ratio is constant until a threshold is reached, and then increases. The thresholds are ranging from 2 to $5 \mathrm{~mW} . \mu \mathrm{m}^{-2}$ and, contrary to compact samples, there is no evidence on the role of nitrogen. 


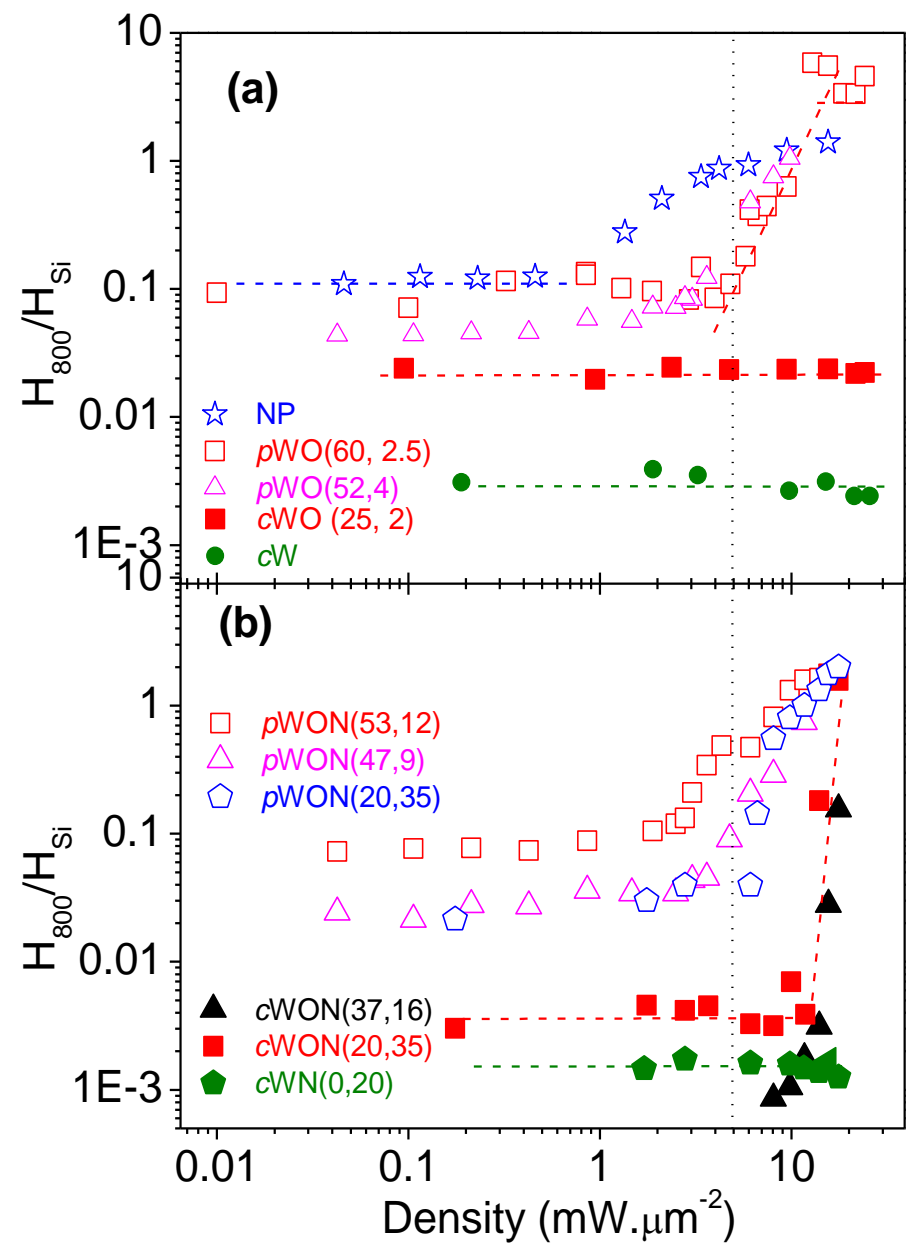

Figure 8. Oxide Raman band intensity evolution as a function of laser power density. The $H_{800} / H_{S i}$ ratio for (a) cW, nanoparticles, and PLD samples without nitrogen and (b) PLD samples containing nitrogen.

\subsection{Qualitative information on the sample temperature during oxide formation.}

When increasing the power density of the laser beam under atmospheric conditions, we have seen previously that sample chemistry can evolve, due to the local heating creating bulk oxides. However, since the laser beam which locally heats the sample is also the beam 
that probes the sample on the exact same spot, the retrieved spectrum is recorded at a sample temperature, which can in principle be higher than room temperature. Figure 9-a shows two spectra taken from the $\operatorname{cWON}(37,16)$ sample: one recorded when the power density was $17 \mathrm{~mW} . \mu \mathrm{m}^{-2}$, the other recorded after this measurement, at a lower power density of $1 \mathrm{~mW} . \mu \mathrm{m}^{-2}$, for which the sample is expected to be close to room temperature. The two spectra are different: at low laser power densities, the $800 \mathrm{~cm}^{-1}$ band slightly upshifts $\left(4 \mathrm{~cm}^{-1}\right)$ and narrows while the band at $700 \mathrm{~cm}^{-1}$ gets more intense and better defined. To obtain hints on the sample temperature due to laser heating, we studied a reference $\mathrm{WO}_{3}$ sample, heated into a furnace (1 bar argon atmosphere, temperatures varied from 20 to $1050^{\circ} \mathrm{C}$ ) equipped with a window that allowed in-situ Raman spectroscopy to be performed. Figure 9-b shows the evolution of the Raman spectrum of this $\mathrm{WO}_{3}$ sample as a function of temperatures. The laser power was kept low enough to avoid local heating. When the temperature increases, the $800 \mathrm{~cm}^{-1}$ band downshifts and broadens and the band at $700 \mathrm{~cm}^{-1}$ starts to disappear. The effect is reversible (not shown here). Note that $\mathrm{WO}_{3}$ is polymorphic and present a series of transition between $17^{\circ} \mathrm{C}$ and $740{ }^{\circ} \mathrm{C}$, from $\delta-\mathrm{WO}_{3}$ to $\gamma-\mathrm{WO}_{3}$ to $\beta-\mathrm{WO}_{3}$ to $\alpha-\mathrm{WO}_{3}$ (see section 2.3). The $1050^{\circ} \mathrm{C}$ spectrum then corresponds to a spectrum of the $\alpha-W_{3}$ phase. This spectrum being similar to that observed for the sample heated at 17 $\mathrm{mW} . \mu \mathrm{m}^{-2}$ and recorded at $17 \mathrm{~mW} . \mu \mathrm{m}^{-2}$ (figure 9-a), one can conclude that it corresponds to $\alpha-\mathrm{WO}_{3}$, whereas the subsequent $1 \mathrm{~mW} . \mu \mathrm{m}^{-2}$ corresponds to $\gamma-\mathrm{WO}_{3}$ (with defects, as widths are larger than the reference well crystallized sample). However, one cannot conclude exactly on the value of the reached temperature due to laser heating because Raman spectra of $\mathrm{WO}_{3}$ are sensitive to the crystal order and to the presence of defects (here for example, the two spectra at room temperature of figure 9-a and 9-b are not strictly similar). However, one can conclude the sample reached an elevated temperature. 


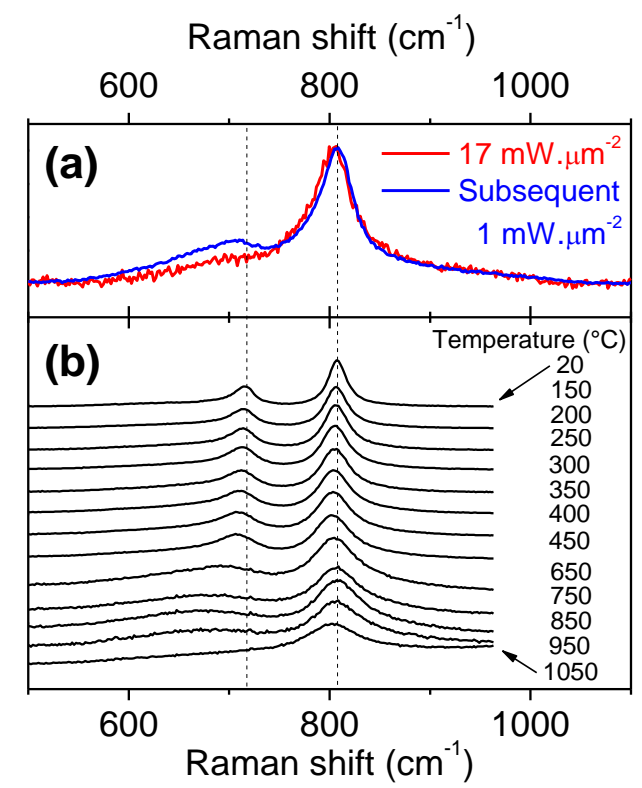

Figure 9. Crystalline phase $\mathrm{cWON}(37,16)$ heated at $17 \mathrm{~mW} \mu \mathrm{m}^{2}$. (a) Spectra recorded at 17 $\mathrm{mW} . \mu \mathrm{m}^{-2}$ and at $1 \mathrm{~mW} . \mu \mathrm{m}^{-2}$ after the $17 \mathrm{~mW} \mu \mathrm{m}^{2}$ irradiation (spectra have been normalized for clarity) (b) Spectra of a reference $\mathrm{WO}_{3}$ sample recorded in a heating cell (see details in the text).

\section{Discussion and concluding remarks}

We have investigated the sensitivity of Raman spectroscopy to tungsten oxide and nitride that could be formed in compact, porous and nanoparticle forms. In the perspective of a tokamak post-mortem campaign, this technique has the advantage to give rapidly a large amount of data based on semi-qualitative spectroscopic observations. This could be used to select samples that need to be quantitatively analyzed with more time-consuming techniques, like TOF-ERDA or electron microscopies. The main spectroscopic findings observed on relevant laboratory samples are:

(1) Raman spectroscopy is sensitive enough to detect surface native oxides, and the optimal experimental conditions to perform such measurements were derived

(2) More tungsten oxides are detected for porous materials and nanoparticles than for compact ones due to the large roughness of the former class of materials

(3) Raman band intensity varies and increases qualitatively with the $O$ content

(4) The crystallographic structure has an influence on band intensities

(5) Long-time storing of a sample between its production and analysis can affect the results because of the growth native oxide in the meantime

(6) Porous materials are less thermally stable than compact materials

(7) The relative thermal stability of compact materials is deteriorated by an increasing nitrogen content

(8) Oxides and nitrides can be detected and distinguished (directly by the presence of additional broad bands in the range $300-600 \mathrm{~cm}^{-1}$, and indirectly by the W PDOS 
activation close to $200 \mathrm{~cm}^{-1}$, for nitrides), even if sensitivity to $\mathrm{N}$ is lower than that of $\mathrm{O}$

(9) An oxygen/nitrogen substitution occurs when the temperature is high, and oxide is created under the laser beam

We believe this work will also be useful for Laser cleaning activities [76], mirror activities [77-80], tungsten oxide engineering activities [54, 81-84], N/O substitution in $\mathrm{W}$, and characterization of new tungsten nitride phases [85], involved for example in water splitting [86]. Two natural continuations of this work could be: studying the kinetics of growth after exposure to air, and detection/quantification of hydrogen isotopes introduced in these materials.

Note that to obtain more quantitative results, details of light propagation inside these complex materials should be considered. The stoichiometry as well as the roughness and the porosity can change optical properties and thus Raman band intensities. For example, oxides with a O/W atomic ratio of 2.7 are at the edge of a metallic/insulator transition [70], thus with totally different optical properties.

The phenomenological points evidenced in this paper, if Raman spectroscopy is used as the first post-mortem technique could be of importance for systematic measurement done in the framework of post-mortem campaigns as these measurements could be done rapidly on many samples. Moreover, statistics could be achieved in a reasonable time scale, even on a single sample, due to the lateral micrometric resolution

\section{Acknowledgements}

This work has been carried out within the framework of the EUROfusion Consortium and has received funding from the Euratom research and training programme 2014-2018 and 20192020 under grant agreement No 633053. The views and opinions expressed herein do not necessarily reflect those of the European Commission. Work performed under EUROfusion WP PFC.

M. M. has received funding from the Excellence Initiative of Aix-Marseille University A*Midex, a French "Investissements d'Avenir" programme as well as from the ANR under grant ANR-18-CE05-12

\section{References}

[1] E. Vassallo, G. Angella, R. Caniello, S. Deambrosis, F. Inzoli, E. Miorin, M. Pedroni, Effects of Nitrogen Concentration on Microstructure of Tungsten Coatings Synthesized by Plasma Sputtering Method, Journal of Fusion Energy, 34 (2015) 1246-1251. 
[2] J. Linke, J. Du, T. Loewenhoff, G. Pintsuk, B. Spilker, I. Steudel, M. Wirtz, Challenges for plasmafacing components in nuclear fusion, Matter and Radiation at Extremes, 4 (2019) 056201.

[3] D.N. Hill, A review of ELMs in divertor tokamaks, Journal of Nuclear Materials, 241 (1997) 182198.

[4] Y. Huang, J.Z. Sun, W.P. Hu, C.F. Sang, D.Z. Wang, Two-dimensional numerical study of ELMsinduced erosion of tungsten divertor target tiles with different edge shapes, Fusion Engineering and Design, 102 (2016) 28-35.

[5] R.A. Pitts, S. Carpentier, F. Escourbiac, T. Hirai, V. Komarov, S. Lisgo, A.S. Kukushkin, A. Loarte, M. Merola, A.S. Naik, R. Mitteau, M. Sugihara, B. Bazylev, P.C. Stangeby, A full tungsten divertor for ITER: Physics issues and design status, Journal of Nuclear Materials, 438 (2013) S48-S56.

[6] S. Brezinsek, J.W. Coenen, T. Schwarz-Selinger, K. Schmid, A. Kirschner, A. Hakola, F.L. Tabares, H.J. van der Meiden, M.L. Mayoral, M. Reinhart, E. Tsitrone, T. Ahlgren, M. Aints, M. Airila, S.

Almaviva, E. Alves, T. Angot, V. Anita, R.A. Parra, F. Aumayr, M. Balden, J. Bauer, M. Ben Yaala, B.M. Berger, R. Bisson, C. Bjorkas, I.B. Radovic, D. Borodin, J. Bucalossi, J. Butikova, B. Butoi, I. Cadez, R. Caniello, L. Caneve, G. Cartry, N. Catarino, M. Cekada, G. Ciraolo, L. Ciupinski, F. Colao, Y. Corre, C. Costin, T. Craciunescu, A. Cremona, M. De Angeli, A. de Castro, R. Dejarnac, D. Dellasega, P. Dinca, T. Dittmar, C. Dobrea, P. Hansen, A. Drenik, T. Eich, S. Elgeti, D. Falie, N. Fedorczak, Y. Ferro, T. Fornal, E. Fortuna-Zalesna, L. Gao, P. Gasior, M. Gherendi, F. Ghezzi, Z. Gosar, H. Greuner, E. Grigore, C. Grisolia, M. Groth, M. Gruca, J. Grzonka, J.P. Gunn, K. Hassouni, K. Heinola, T. Hoschen, S. Huber, W. Jacob, I. Jepu, X. Jiang, I. Jogi, A. Kaiser, J. Karhunen, M. Kelemen, M. Koppen, H.R. Koslowski, A. Kreter, M. Kubkowska, M. Laan, L. Laguardia, A. Lahtinen, A. Lasa, V. Lazic, N. Lemahieu, J. Likonen, J. Linke, A. Litnovsky, C. Linsmeier, T. Loewenhoff, C. Lungu, M. Lungu, G. Maddaluno, H. Maier, T. Makkonen, A. Manhard, Y. Marandet, S. Markelj, L. Marot, C. Martin, A.B. Martin-Rojo, Y. Martynova, R. Mateus, D. Matveev, M. Mayer, G. Meisl, N. Mellet, A. Michau, J. Miettunen, S. Moller, T.W. Morgan, J. Mougenot, M. Mozetic, V. Nemanic, R. Neu, K. Nordlund, M. Oberkofler, E. Oyarzabal, M. Panjan, C. Pardanaud, P. Paris, M. Passoni, B. Pegourie, P. Pelicon, P. Petersson, K. Piip, G. Pintsuk, G.O. Pompilian, G. Popa, C. Porosnicu, G. Primc, M. Probst, J. Raisanen, M. Rasinski, S. Ratynskaia, D. Reiser, D. Ricci, M. Richou, J. Riesch, G. Riva, M. Rosinski, P. Roubin, M. Rubel, C. Ruset, E. Safi, G. Sergienko, Z. Siketic, A. Sima, B. Spilker, R. Stadlmayr, I. Steudel, P. Strom, T. Tadic, D. Tafalla, I. Tale, D. Terentyev, A. Terra, V. Tiron, I. Tiseanu, P. Tolias, D. Tskhakaya, A. Uccello, B. Unterberg, I. Uytdenhoven, E. Vassallo, P. Vavpetic, P. Veis, I.L. Velicu, J.W.M. Vernimmen, A. Voitkans, U. von Toussaint, A. Weckmann, M. Wirtz, A. Zaloznik, R. Zaplotnik, W.P. Contributors, Plasma-wall interaction studies within the EUROfusion consortium: progress on plasma-facing components development and qualification, Nuclear Fusion, 57 (2017).

[7] M. Mayer, S. Krat, A. Baron-Wiechec, Y. Gasparyan, K. Heinola, S. Koivuranta, J. Likonen, C. Ruset, G. de Saint-Aubin, A. Widdowson, J.E.T. Contributors, Erosion and deposition in the JET divertor during the second ITER-like wall campaign, Physica Scripta, T170 (2017) 014058.

[8] H. Greuner, H. Maier, M. Balden, C. Linsmeier, B. Boswirth, S. Lindig, P. Norajitra, S. Antusch, M. Rieth, Investigation of European tungsten materials exposed to high heat flux $\mathrm{H} / \mathrm{He}$ neutral beams, Journal of Nuclear Materials, 442 (2013) S256-S260.

[9] S. Brezinsek, A. Widdowson, M. Mayer, V. Philipps, P. Baron-Wiechec, J.W. Coenen, K. Heinola, A. Huber, J. Likonen, P. Petersson, M. Rubel, M.F. Stamp, D. Borodin, J.P. Coad, A.G. Carrasco, A. Kirschner, S. Krat, K. Krieger, B. Lipschultz, C. Linsmeier, G.F. Matthews, K. Schmid, J.E.T. Contributors, Beryllium migration in JET ITER-like wall plasmas, Nuclear Fusion, 55 (2015) 063021.

[10] I. Bykov, H. Bergsaker, G. Possnert, Y. Zhou, K. Heinola, J. Pettersson, S. Conroy, J. Likonen, P. Petersson, A. Widdowson, J.E.T. Contributors, Studies of Be migration in the JET tokamak using AMS with Be-10 marker, Nuclear Instruments \& Methods in Physics Research Section B-Beam Interactions with Materials and Atoms, 371 (2016) 370-375.

[11] M. Kumar, C. Makepeace, C. Pardanaud, Y. Ferro, E. Hodille, C. Martin, P. Roubin, A. Widdowson, T. Dittmar, C.H. Linsmeier, C.P. Lungu, C. Porosnicu, I. Jepu, P. Dinca, M. Lungu, O.G. Pompilian, J.E.T. Contributors, Identification of $\mathrm{BeO}$ and BeOxDy in melted zones of the JET Be limiter tiles: Raman study using comparison with laboratory samples, Nuclear Materials and Energy, 17 (2018) 295-301. 
[12] C. Makepeace, C. Pardanaud, P. Roubin, I. Borodkina, C. Ayrese, P. Coade, A. Baron-Wiechec, I. Jepu, K. Heinola, A. Widdowson, S. Lozano-Perez, J.E.T. Contributors, The effect of beryllium oxide on retention in JET ITER-like wall tiles, Nuclear Materials and Energy, 19 (2019) 346-351.

[13] M. Oberkofler, D. Alegre, F. Aumayr, S. Brezinsek, T. Dittmar, K. Dobes, D. Douai, A. Drenik, M. Koppen, U. Kruezi, C. Linsmeier, C.P. Lungu, G. Meisl, M. Mozetic, C. Porosnicu, V. Rohde, S.G. Romanelli, A.U. Team, J.E. Contributors, Plasma-wall interactions with nitrogen seeding in all-metal fusion devices: Formation of nitrides and ammonia, Fusion Engineering and Design, 98-99 (2015) 1371-1374.

[14] S. Markelj, A. Zaloznik, I. Cadez, Interaction of ammonia and hydrogen with tungsten at elevated temperature studied by gas flow through a capillary, Journal of Vacuum Science \& Technology A, 35 (2017) 061602.

[15] E. Fortuna-Zalesna, J. Grzonka, S. Moon, M. Rubel, P. Petersson, A. Widdowson, J.E.T. Contributors, Fine metal dust particles on the wall probes from JET-ILW, Physica Scripta, T170 (2017) 014038.

[16] E. Fortuna-Zalesna, J. Grzonka, M. Rubel, A. Garcia-Carrasco, A. Widdowson, A. Baron-Wiechec, L. Ciupinski, J.E.T. Contributors, Studies of dust from JET with the ITER-Like Wall: Composition and internal structure, Nuclear Materials and Energy, 12 (2017) 582-587.

[17] S. Masuzakil, M. Tokitanii, T. Otsuka, Y. Oya, Y. Hatan, M. Miyamoto, R. Sakamoto, N. Ashikawa, S. Sakurada, Y. Uemura, K. Azuma, K. Yumizurus, M. Oyaizu, T. Suzuki, H. Kurotaki, D. Hamaguchi, K. Isobel, N. Asakura, A. Widdowson, K. Heinola, S. Jachmich, M. Rubel, J.E.T. contributors, Analyses of microstructure, composition and retention of hydrogen isotopes in divertor tiles of JET with the ITERlike wall, Physica Scripta, T170 (2017) 014031.

[18] K. Heinola, A. Widdowson, J. Likonen, E. Alves, A. Baron-Wiechec, N. Barradas, S. Brezinsek, N. Catarino, P. Coad, S. Koivuranta, Long-term fuel retention in JET ITER-like wall, Physica Scripta, T167 (2016) 014075.

[19] J. Likonen, K. Heinola, A. De Backer, S. Koivuranta, A. Hakola, C.F. Ayres, A. Baron-Wiechec, P. Coad, G.F. Matthews, M. Mayer, A. Widdowson, J. Contributors, Deuterium trapping and release in JET ITER-like wall divertor tiles, Physica Scripta, T167 (2016) 014074.

[20] E. Bernard, R. Sakamoto, E. Hodille, A. Kreter, E. Autissier, M.F. Barthe, P. Desgardin, T. SchwarzSelinger, V. Burwitz, S. Feuillastre, S. Garcia-Argote, G. Pieters, B. Rousseau, M. lalovega, R. Bisson, F. Ghiorghiu, C. Corr, M. Thompson, R. Doerner, S. Markelj, H. Yamada, N. Yoshid, C. Grisolia, Tritium retention in W plasma-facing materials: Impact of the material structure and helium irradiation, Nuclear Materials and Energy, 19 (2019) 403-410.

[21] G.F. Matthews, M. Beurskens, S. Brezinsek, M. Groth, E. Joffrin, A. Loving, M. Kear, M.L. Mayoral, R. Neu, P. Prior, V. Riccardo, F. Rimini, M. Rubel, G. Sips, E. Villedieu, P. de Vries, M.L. Watkins, E.-J. Contributors, JET ITER-like wall-overview and experimental programme, Physica Scripta, T145 (2011) 014001.

[22] J. Bucalossi, M. Missirlian, P. Moreau, F. Samaille, E. Tsitrone, D. van Houtte, T. Batal, C. Bourdelle, M. Chantant, Y. Corre, X. Courtois, L. Delpech, L. Doceul, D. Douai, H. Dougnac, F. Faisse, C. Fenzi, F. Ferlay, M. Firdaouss, L. Gargiulo, P. Garin, C. Gil, A. Grosman, D. Guilhem, J. Gunn, C. Hernandez, D. Keller, S. Larroque, F. Leroux, M. Lipa, P. Lotte, A. Martinez, O. Meyer, F. Micolon, P. Mollard, E. Nardon, R. Nouailletas, A. Pilia, M. Richou, S. Salasca, J.M. Travere, The WEST project: Testing ITER divertor high heat flux component technology in a steady state tokamak environment, Fusion Engineering and Design, 89 (2014) 907-912.

[23] M. Richou, M. Missirlian, D. Guilhem, M. Lipa, P. Languille, F. Ferlay, F. Gallay, H. Greuner, C. Hernandez, M. Firdaouss, J. Bucalossi, Design and preliminary thermal validation of the WEST actively cooled upper divertor, Fusion Engineering and Design, 98-99 (2015) 1394-1398.

[24] A. Kreter, C. Brandt, A. Huber, S. Kraus, S. Moller, M. Reinhart, B. Schweer, G. Sergienko, B. Unterberg, LINEAR PLASMA DEVICE PSI-2 FOR PLASMA-MATERIAL INTERACTION STUDIES, Fusion Science and Technology, 68 (2015) 8-14.

[25] C. Linsmeier, B. Unterberg, J.W. Coenen, R.P. Doerner, H. Greuner, A. Kreter, J. Linke, H. Maier, Material testing facilities and programs for plasma-facing component testing, Nuclear Fusion, 57 (2017) 092012. 
[26] V.K. Alimov, B. Tyburska, M. Balden, S. Lindig, J. Roth, K. Isobe, T. Yamanishi, Surface morphology and deuterium retention in tungsten oxide layers exposed to low-energy, high flux $D$ plasma, Journal of Nuclear Materials, 409 (2011) 27-32.

[27] J.W. Coenen, V. Philipps, S. Brezinsek, G. Pintsuk, T. Tanabe, Y. Ueda, U. Samm, T. Team, Analysis of structural changes and high-heat-flux tests on pre-damaged tungsten from tokamak melt experiments, Physica Scripta, T145 (2011) 014066.

[28] M. Richou, M. Missirlian, E. Tsitrone, J. Bucalossi, C. Desgranges, M. Firdaouss, D. Guilhem, H. Greuner, C. Hernandez, M. Lipa, G. Pintsuk, F. Samaille, The WEST project: validation program for WEST tungsten coated plasma facing components, Physica Scripta, T167 (2016) 014029.

[29] F. Schoofs, M. Gorley, A route to standardised high heat flux testing: An example for tungsten, Fusion Engineering and Design, 139 (2019) 132-136.

[30] L.C. Alves, E. Alves, N.P. Barradas, R. Mateus, P. Carvalho, J.P. Coad, A.M. Widdowson, J. Likonen, S. Koivuranta, Erosion and re-deposition processes in JET tiles studied with ion beams, Nuclear Instruments \& Methods in Physics Research Section B-Beam Interactions with Materials and Atoms, 268 (2010) 1991-1996.

[31] J. Guterl, R.D. Smirnov, S.I. Krasheninnikov, M. Zibrov, A.A. Pisarev, Theoretical analysis of deuterium retention in tungsten plasma-facing components induced by various traps via thermal desorption spectroscopy, Nuclear Fusion, 55 (2015) 093017.

[32] E.A. Hodille, Y. Ferro, N. Fernandez, C.S. Becquart, T. Angot, J.M. Layet, R. Bisson, C. Grisolia, Study of hydrogen isotopes behavior in tungsten by a multi trapping macroscopic rate equation model, Physica Scripta, T167 (2016) 014011.

[33] E.A. Hodille, F. Ghiorghiu, Y. Addab, A. Zaloznik, M. Minissale, Z. Piazza, C. Martin, T. Angot, L. Gallais, M.F. Barthe, C.S. Becquart, S. Markelj, J. Mougenot, C. Grisolia, R. Bisson, Retention and release of hydrogen isotopes in tungsten plasma-facing components: the role of grain boundaries and the native oxide layer from a joint experiment-simulation integrated approach, Nuclear Fusion, 57 (2017) 076019.

[34] E.A. Hodille, Y. Ferro, Z.A. Piazza, C. Pardanaud, Hydrogen in beryllium oxide investigated by DFT: on the relative stability of charged-state atomic versus molecular hydrogen, Journal of PhysicsCondensed Matter, 30 (2018) 305201.

[35] Y. Addab, C. Martin, C. Pardanaud, J. Khayadjian, K. Achkasov, D. Kogut, G. Cartry, G. Giacometti, M. Cabie, J.L. Gardarein, P. Roubin, Formation of thin tungsten oxide layers: characterization and exposure to deuterium, Physica Scripta, T167 (2016) 014036.

[36] H. Hijazi, Y. Addab, A. Maan, J. Duran, D. Donovan, C. Pardanaud, M. Ibrahim, M. Cabie, P. Roubin, C. Martin, Tungsten oxide thin film exposed to low energy He plasma: Evidence for a thermal enhancement of the erosion yield, Journal of Nuclear Materials, 484 (2017) 91-97.

[37] C. Martin, H. Hijazi, Y. Addab, B. Domenichini, M.E. Bannister, F.W. Meyer, C. Pardanaud, G. Giacometti, M. Cabie, P. Roubin, Tungsten oxide thin film bombarded with a low energy He ion beam: evidence for a reduced erosion and W enrichment, Physica Scripta, T170 (2017) 014019. [38] M. Ahmadi, S. Sahoo, R. Younesi, A.P.S. Gaur, R.S. Katiyar, M.J.F. Guinel, WO3 nano-ribbons: their phase transformation from tungstite (WO3 center dot $\mathrm{H} 2 \mathrm{O}$ ) to tungsten oxide (WO3), Journal of Materials Science, 49 (2014) 5899-5909.

[39] T. Pagnier, M. Boulova, N. Sergent, P. Bouvier, G. Lucazeau, Nanopowders and nanostructured oxides: phase transitions and surface reactivity, Journal of Raman Spectroscopy, 38 (2007) 756-761. [40] M.I. Rusu, C. Pardanaud, Y. Ferro, G. Giacometti, C. Martin, Y. Addab, P. Roubin, M. Minissale, L. Ferri, F. Virot, M. Barrachin, C.P. Lungu, C. Porosnicu, P. Dinca, M. Lungu, M. Koppen, P. Hansen, C. Linsmeier, Preparing the future post-mortem analysis of beryllium-based JET and ITER samples by multi-wavelengths Raman spectroscopy on implanted Be, and co-deposited Be, Nuclear Fusion, 57 (2017) 076035.

[41] C. Arnas, A. Chami, L. Couedel, T. Acsente, M. Cabie, T. Neisius, Thermal balance of tungsten monocrystalline nanoparticles in high pressure magnetron discharges, Physics of Plasmas, 26 (2019) 053706.

[42] D. Dellasega, G. Merlo, C. Conti, C.E. Bottani, M. Passoni, Nanostructured and amorphous-like tungsten films grown by pulsed laser deposition, Journal of Applied Physics, 112 (2012) 084328. 
[43] A. Pezzoli, D. Dellasega, V. Russo, A. Gallo, P.A.Z. van Emmichoven, M. Passoni, Thermal annealing and exposure to divertor-like deuterium plasma of tailored tungsten oxide coatings, Journal of Nuclear Materials, 463 (2015) 1041-1044.

[44] Z. Siketic, I.B. Radovic, M. Jaksic, Development of a time-of-flight spectrometer at the Ruder Boskovic Institute in Zagreb, Nuclear Instruments \& Methods in Physics Research Section B-Beam Interactions with Materials and Atoms, 266 (2008) 1328-1332.

[45] Z. Siketic, N. Skukan, I.B. Radovic, A gas ionisation detector in the axial (Bragg) geometry used for the time-of-flight elastic recoil detection analysis, Rev. Sci. Instrum., 86 (2015) 083301.

[46] R. Mateus, D. Dellasega, M. Passoni, Z. Siketic, I.B. Radovic, A. Hakola, E. Alves, Helium load on W-O coatings grown by pulsed laser deposition, Surface \& Coatings Technology, 355 (2018) 215-221. [47] R. Yan, L. Moser, B.G. Wang, J. Peng, C. Vorpahl, F. Leipold, R. Reichle, R. Ding, J.L. Chen, L. Mu, R. Steiner, E. Meyer, M.Z. Zhao, J.H. Wu, L. Marot, Plasma cleaning of ITER edge Thomson scattering mock-up mirror in the EAST tokamak, Nuclear Fusion, 58 (2018) 026008.

[48] M.L. Addonizio, A. Castaldo, A. Antonaia, E. Gambale, L. lemmo, Influence of process parameters on properties of reactively sputtered tungsten nitride thin films, Journal of Vacuum Science \& Technology A, 30 (2012) 031506.

[49] M. Boulova, G. Lucazeau, Crystallite nanosize effect on the structural transitions of WO3 studied by Raman spectroscopy, Journal of Solid State Chemistry, 167 (2002) 425-434.

[50] M. Boulova, N. Rosman, P. Bouvier, G. Lucazeau, High-pressure Raman study of microcrystalline WO3 tungsten oxide, Journal of Physics-Condensed Matter, 14 (2002) 5849-5863.

[51] C.I. Vargas-Consuelos, K. Seo, M. Camacho-Lopez, O.A. Graeve, Correlation between Particle Size and Raman Vibrations in WO3 Powders, Journal of Physical Chemistry C, 118 (2014) 9531-9537.

[52] H.D. Zheng, J.Z. Ou, M.S. Strano, R.B. Kaner, A. Mitchell, K. Kalantar-Zadeh, Nanostructured Tungsten Oxide - Properties, Synthesis, and Applications, Advanced Functional Materials, 21 (2011) 2175-2196.

[53] K. Thummavichai, N.N. Wang, F. Xu, G. Rance, Y.D. Xia, Y.Q. Zhu, In situ investigations of the phase change behaviour of tungsten oxide nanostructures, Royal Society Open Science, 5 (2018) 171932.

[54] D.B. Migas, V.L. Shaposhnikov, V.E. Borisenko, Tungsten oxides. II. The metallic nature of Magneli phases, Journal of Applied Physics, 108 (2010) 093714.

[55] Y. Addab, C. Martin, C. Pardanaud, J. Khayadjian, K. Achkasov, D. Kogut, G. Cartry, G. Giacometti, M. Cabié, J.L. Gardarein, Formation of thin tungsten oxide layers: characterization and exposure to deuterium, Physica Scripta, T167 (2016) 014036.

[56] A. Baserga, V. Russo, F. Di Fonzo, A. Bailini, D. Cattaneo, C.S. Casari, A.L. Bassi, C.E. Bottani, Nanostructured tungsten oxide with controlled properties: Synthesis and Raman characterization, Thin Solid Films, 515 (2007) 6465-6469.

[57] J. Chen, D.Y. Lu, W.H. Zhang, F.Y. Xie, J. Zhou, L. Gong, X. Liu, S.Z. Deng, N.S. Xu, Synthesis and Raman spectroscopic study of W20058 nanowires, Journal of Physics D-Applied Physics, 41 (2008) 115305.

[58] A.V. Khotkevich, I.K. Yanson, Atlas of Point Contact Spectra of Electron-Phonon Interactions in Metals, Springer, 1995.

[59] C. Pardanaud, E. Areou, C. Martin, R. Ruffe, T. Angot, P. Roubin, C. Hopf, T. Schwarz-Selinger, W. Jacob, Raman micro-spectroscopy as a tool to measure the absorption coefficient and the erosion rate of hydrogenated amorphous carbon films heat-treated under hydrogen bombardment, Diamond Relat. Mater., 22 (2012) 92-95.

[60] M. Castro, R. Cuerno, M. Nicoli, L. Vazquez, J.G. Buijnsters, Universality of cauliflower-like fronts: from nanoscale thin films to macroscopic plants, New Journal of Physics, 14 (2012) 103039.

[61] J.R. Rumble, D.M. Bickham, C.J. Powell, THE NIST X-RAY PHOTOELECTRON-SPECTROSCOPY DATABASE, Surface and Interface Analysis, 19 (1992) 241-246.

[62] G.P. Halada, C.R. Clayton, COMPARISON OF MO-N AND W-N SYNERGISM DURING PASSIVATION OF STAINLESS-STEEL THROUGH X-RAY PHOTOELECTRON-SPECTROSCOPY AND ELECTROCHEMICAL ANALYSIS, Journal of Vacuum Science \& Technology a-Vacuum Surfaces and Films, 11 (1993) 23422347. 
[63] F. Kerkhof, J.A. Moulijn, A. Heeres, XPS SPECTRA OF METATHESIS CATALYST TUNGSTEN-OXIDE ON SILICA-GEL, Journal of Electron Spectroscopy and Related Phenomena, 14 (1978) 453-466.

[64] C. Metaxa, B.D. Ozsdolay, T. Zorba, K. Paraskevopoulos, D. Gall, P. Patsalas, Electronic and optical properties of rocksalt-phase tungsten nitride (B1-WN), Journal of Vacuum Science \& Technology A, 35 (2017) 031501.

[65] Y.P. Zhu, G. Chen, Y.J. Zhong, W. Zhou, Z.P. Shao, Rationally Designed Hierarchically Structured Tungsten Nitride and Nitrogen-Rich Graphene-Like Carbon Nanocomposite as Efficient Hydrogen Evolution Electrocatalyst, Advanced Science, 5 (2018) 1700603.

[66] C. pardanaud, C. Martin, P. Roubin, Raman Microscopy: A Suitable Tool for Characterizing Surfaces in Interaction with Plasmas in the Field of Nuclear Fusion, in: K. Maaz (Ed.) Raman Spectroscopy and Applications, InTech, 2017, pp. 3-30.

[67] A. Elbe, G. Meister, A. Goldmann, Vibrational modes of atomic oxygen on W(110), Surface Science, 371 (1997) 438-444.

[68] Y.Q. Sheng, E. Recknagel, A. Weidinger, Z.G. Gu, Z.Y. Lai, Z.C. Zhuang, RAMAN-SCATTERING AT THE CAF2 CRYSTAL-SURFACE EXCITED BY AN EVANESCENT OPTICAL-WAVE FIELD, Physica Status Solidi B-Basic Research, 145 (1988) 151-156.

[69] C. Pardanaud, M.I. Rusu, G. Giacometti, C. Martin, Y. Addab, P. Roubin, C.P. Lungu, C. Porosnicu, I. Jepu, P. Dinca, M. Lungu, O.G. Pompilian, R. Mateus, E. Alves, M. Rubel, J. contributors, Raman microscopy investigation of beryllium materials, Physica Scripta, T167 (2016) 014027.

[70] E. Besozzi, D. Dellasega, V. Russo, C. Conti, M. Passoni, M.G. Beghi, Thermomechanical properties of amorphous metallic tungsten-oxygen and tungsten-oxide coatings, Materials \& Design, 165 (2019) 107565.

[71] J.W. Klaus, S.J. Ferro, S.M. George, Atomically controlled growth of tungsten and tungsten nitride using sequential surface reactions, Applied Surface Science, 162 (2000) 479-491.

[72] L. Maille, C. Sant, C. Le Paven-Thivet, C. Legrand-Buscema, P. Garnier, Structure and morphological study of nanometer W and W3O thin films, Thin Solid Films, 428 (2003) 237-241. [73] D. Yoon, H. Moon, Y.W. Son, J.S. Choi, B.H. Park, Y.H. Cha, Y.D. Kim, H. Cheong, Interference effect on Raman spectrum of graphene on SiO2/Si, Physical Review B, 80 (2009) 125422.

[74] A.D. Rakic, A.B. Djurisic, J.M. Elazar, M.L. Majewski, Optical properties of metallic films for vertical-cavity optoelectronic devices, Applied Optics, 37 (1998) 5271-5283.

[75] M. Minissale, C. Pardanaud, R. Bisson, L. Gallais, The temperature dependence of optical properties of tungsten in the visible and near-infrared domains: an experimental and theoretical study, Journal of Physics D-Applied Physics, 50 (2017) 455601.

[76] A. Maffini, A. Uccello, D. Dellasega, M. Passoni, Laser cleaning of diagnostic mirrors from tungsten-oxygen tokamak-like contaminants, Nuclear Fusion, 56 (2016) 086008.

[77] D. Ivanova, M. Rubel, A. Widdowson, P. Petersson, J. Likonen, L. Marot, E. Alves, A. GarciaCarrasco, G. Pintsuk, J.-E. Contributors, An overview of the comprehensive First Mirror Test in JET with ITER-like wall, Physica Scripta, T159 (2014) 014011.

[78] L. Moser, L. Marot, R. Steiner, R. Reichle, F. Leipold, C. Vorpahl, F. Le Guern, U. Walach, S. Alberti, I. Furno, R. Yan, J. Peng, M. Ben Yaala, E. Meyer, Plasma cleaning of ITER first mirrors, Physica Scripta, T170 (2017) 014047.

[79] A. Garcia-Carrasco, P. Petersson, M. Rubel, A. Widdowson, E. Fortuna-Zalesna, S. Jachmich, M. Brix, L. Marot, J.E.T. Contributors, Plasma impact on diagnostic mirrors in JET, Nuclear Materials and Energy, 12 (2017) 506-512.

[80] A. Litnovsky, V.S. Voitsenya, R. Reichle, M. Walsh, A. Razdobarin, A. Dmitriev, N. Babinov, L. Marot, L. Moser, R. Yan, M. Rubel, A. Widdowson, S. Moon, S.G. Oh, Y. An, P. Shigin, I. Orlovskiy, K.Y. Vukolov, E. Andreenko, A. Krimmer, V. Kotov, P. Mertens, I.T.G. Diagnostics, Diagnostic mirrors for ITER: research in the frame of International Tokamak Physics Activity, Nuclear Fusion, 59 (2019) 066029.

[81] S.C. Cifuentes, M.A. Monge, P. Perez, On the oxidation mechanism of pure tungsten in the temperature range 600-800 degrees C, Corrosion Science, 57 (2012) 114-121.

[82] Z.F. Huang, J.J. Song, L. Pan, X.W. Zhang, L. Wang, J.J. Zou, Tungsten Oxides for Photocatalysis, Electrochemistry, and Phototherapy, Advanced Materials, 27 (2015) 5309-5327. 
[83] N. Zhang, X.Y. Li, H.C. Ye, S.M. Chen, H.X. Ju, D.B. Liu, Y. Lin, W. Ye, C.M. Wang, Q. Xu, J.F. Zhu, L. Song, J. Jiang, Y.J. Xiong, Oxide Defect Engineering Enables to Couple Solar Energy into Oxygen Activation, Journal of the American Chemical Society, 138 (2016) 8928-8935.

[84] W. Wang, H.X. Wen, S. Ling, Z.T. Li, J.B. Su, C.B. Wang, Self-doped W-WOx nanocermet multilayer films fabricated by single tungsten target reactive sputtering for selective solar absorption, Journal of Materials Chemistry A, 6 (2018) 15690-15700.

[85] S.M. Wang, X.H. Yu, Z.J. Lin, R.F. Zhang, D.W. He, J.Q. Qin, J.L. Zhu, J. Han, L. Wang, H.K. Mao, J.Z. Zhang, Y.S. Zhao, Synthesis, Crystal Structure, and Elastic Properties of Novel Tungsten Nitrides, Chemistry of Materials, 24 (2012) 3023-3028.

[86] N. Han, P.Y. Liu, J. Jiang, L.H. Ai, Z.P. Shao, S.M. Liu, Recent advances in nanostructured metal nitrides for water splitting, Journal of Materials Chemistry A, 6 (2018) 19912-19933. 